NBER WORKING PAPER SERIES

JUMPS AND STOCHASTIC VOLATILITY:
EXCHANGE RATE PROCESSES IMPLICIT
IN PHLX DEUTSCHEMARK OPTIONS

David S. Bates

Working Paper No. 4596

\author{
NATIONAL BUREAU OF ECONOMIC RESEARCH \\ 1050 Massachusetus Avenue \\ Cambridge, MA 02138 \\ December, 1993
}

Financial support from the Geewax-Terker Research Program in Financial Instruments and from the Weiss Center for Intemational Financial Research is gratefully acknowledged. I am indebted to Sandy Grossman for helpful comments on an earlier draft of this paper, and for provision of some of the data used in this study. This paper is part of NBER's research program in Asset Pricing. Any opinions expressed are those of the author and not those of the National Bureau of Economic Research. 
NBER Working Paper \#4596

December 1993

\title{
JUMPS AND STOCHASTIC VOLATILITY: \\ EXCHANGE RATE PROCESSES IMPLICIT \\ IN PHLX DEUTSCHEMARK OPTIONS
}

\begin{abstract}
An efficient method is developed for pricing American options on combination stochastic volatility/jump-diffusion processes when jump risk and volatility. risk are systematic and nondiversifiable, thereby nesting two major option pricing models. The parameters implicit in PHLX-traded Deutschemark options of the stochastic volatility/jump-diffusion model and various submodels are estimated over 1984-91, and are tested for consistency with the \$/DM futures process and the implicit volatility sample path. The parameters implicit in options are found to be inconsistent with the time series properties of implicit volatilities, but qualitatively consistent with log-differenced futures prices. No economically significant implicit expectations of exchange rate jumps were found in full-sample estimation, which is consistent with the reduced leptokurtosis of \$/DM weekly exchange rate changes over 1984-91 relative to earlier periods.
\end{abstract}

David S. Bates

Finance Department

The Wharton School

University of Pennsylvania

Philadelphia, PA 19104-6367

and NBER 
A considerable amount of evidence has been amassed regarding the conditional and unconditional moments of exchange rate processes, from time series studies and from option prices. It is undisputed that volatility is time-varying, as evinced in plots of implicit volatilities over time and in the extensive literature on ARCH and GARCH models. Time series studies atso indicate that the unconditional distribution of log-differenced exchange rates is leptokurtic, and that there is an inverse relationship between excess kurtosis and the length of the holding period.' Conditional leptokurtosis has atso been found, in time series studies (fat-tailed residuals from ARCH/GARCH models) and implicit in option prices." The evidence regarding unconditional and conditional skewness is more ambiguous, with time series estimates sensitive to the currency and period used. Studies of option prices have found evidence of substantial positive implicit skewness in options on foreign currencies during 1983-85, but less evidence during more recent periods.'

'For instance, Hsieh (1988) estimated unconditional kurtosis of 12.8 for daily changes in the \$/DM exchange rates, while Meese (1986) estimated kurtosis of 4.2 for monthly returns.

The U-shaped pattern in implicit volatilities across different strike prices documented in Shastri and Wethyavivorn (1987) and Ben Khelifa (1991) is evidence of a conditionally leptokurtic distribution implicit in foreign currency options. Model-specific daily estimates of the implicit distribution in Bates (1988a) tound excess kurtosis in options on DM futures over 1984-87.

${ }^{3}$ Bodurtha and Courtadon (1987) document the tendency of an American option version of the BlackScholes model to overprice in- and at-the-money calls and underprice out-of-the-money calls on foreign currencies during 1983-85, indicating an implicit distribution more positively skewed than the lognormal. Bates (1988a), using a jump-diffusion model, found substantial positive implicit skewness in options on Deutschemark futures during 1984-85 but not during 1986 and 1987. 
Different time series models have been employed to capture these salient features. Assorted stationary fat-tailed distributions such as the stable Paretian (Westerfield 1977), Student-t (Rogalski and Vinso 1978) and jump-diffusions (Akgiray and Booth 1988) have improved on the unconditional distribution relative to a Gaussian benchmark. Stochastic volatility/ARCH models have been used to capture the time-varying variances and some -- though not all -- of the leptokurtosis." More recent approaches in the time series literature have tended to combine fat-tailed distributions and time-varying variances; for instance the Student-t/GARCH model of Baillie and Bollerslev (1989) and the jump-diffusion/ARCH model of Jorion (1989).

Option theory has developed in parallel with the various time series models of exchange rates. Stochastic volatility models have been used by Melino and Turnbull (1990) and Chesney and Scott (1989) to price foreign currency options, while Bates (1988a) and Jorion (1989) have used Merton's (1976) jump-diffusion model to capture the conditional leptokurtosis. Given substantial computing costs in pricing options, a standard approach when testing option pricing models has been to take time series estimates and to examine their implications for the resulting option prices."

The objective of this study is to proceed in the opposite direction, and to examine the evidence from option prices regarding the conditional distribution of log-differenced exchange rates. Given that foreign currency options involve direct bets on the distribution of exchange rate changes, option prices offer valuable insights into the perceived conditional distribution that are not necessarily available from time series studies. For instance, implied volatilities from option prices

'Bollerslev, Chou, and Kroner (1992) provide an excellent survey of the ARCH/GARCH literature, including the applications to foreign exchange rates. (1992).

'Examples include Chesney and Scott (1989), Jorion (1989), Melino and Turnbull (1990), and Cao 
could theoretically summarize all relevant information regarding expected future volatilities, wher eas univariate ARCH and GARCH approaches can exploit only the subset of that information embodied in the past history of asset prices. Equally, option prices should reflect any perceptions of low-frequency large-amplitude jump risk, whereas time series studies lack the power in the small samples typically available to reliably pick up any low-frequency jump component.

Extending the Fourier inversion option pricing methodology of Stein and Stein (1991) and Heston (1993), a tractable and efficient model for pricing American options on combined stochastic volatility/jump-diffusion processes in the presence of systematic volatility and jump risk is developed in Section I. The model and various submodels are then fitted to transactions data for Deutschemark currency options traded on the Philadeiphia Stock Exchange, in Section II.

The paper also develops Fourier inversion techniques for evaluating the likelihood of observed sample paths given specific implicit parameter estimates. Using these, the consistency of the distributions implicit in option prices with the time series properties of implicit volatilities and the \$/DM futures price is tested in Section II. Given an internally consistent stochastic volatility/jump-diffusion model, it is possible to examine rigorously some of the option pricing anomalies discovered by others using an ad hoc Black-Scholes model. For instance: whether the term structure of implicit volatilities is consistent with the time series properties of implicit volatilities (Stein 1991), and whether implicit volatilities are unbiased predictors of future volatility. Joint estimation and likelihood ratio tests are used, in contrast to the two-stage estimation approach of previous studies. Furthermore, a careful distinction is drawn between the "risk-neutral" distributions implicit in option prices and the actual distributions relevant for time series analysis. Section III concludes. 


\section{A proposed stochastic volatility/jump-diffusion model}

The following assumptions will be maintained throughout this paper:

A1) Markets are frictionless: there are no transactions costs or differential taxes, trading can take place continuously, there are no restrictions on borrowing or selling short.

A2) The instantaneous risk-free interest rate $r$ and domestic/foreign interest differential $b=r-r^{*}$ are known and constant.

A3) The exchange rate $S$ (\$/DM) follows a geometric jump-diffusion with the instantaneous conditional variance $V$, following a mean-reverting square root process:

$$
\begin{aligned}
& d S / S-(\mu-\lambda \bar{k}) d t+\sqrt{V} d Z+k d q \\
& d V-(\alpha-\beta V) d t+\sigma_{\nu} \sqrt{V} d Z_{v} \\
& \operatorname{Cov}\left(d Z, d Z_{v}\right)-\rho d t \\
& \operatorname{Prob}(d q-1)-\lambda d t, \ln (1+k)-N\left(\ln (1+\bar{k})-1 / 2 \delta^{2}, \delta^{2}\right)
\end{aligned}
$$

where

$\mu$ is the instantaneous rate of appreciation of the foreign currency;

$\lambda$ is the annual frequency of jumps;

$k$ is the random percentage jump conditional on a jump occurring; and

$d q$ is a Poisson counter with intensity $\lambda$.

The above process for volatility has been used for pricing options under two polar assumptions about interest rate processes. Bailey and Stulz (1989) and Bossaerts and Hillion (1993) price stock index and stock options using the Cox, Ingersoll, and Ross (1984) general equilibrium production economy. which implies instantaneous conditional variances and interest rates are proportional and follow the square root process above. On the other hand, Hull and White (1988) and Heston (1993) price options off the above stochastic volatility process under the more tractable assumption of constant interest rates. Since Scott (1993) shows that interest rate volatility has little impact on short-term option prices such as those examined in this study, the latter assumption of constant domestic and foreign interest rates will be maintained in this study. 
The stochastic volatility process behaves fairly similarly to the alter nate popular specification of an Ornstein-Uhlenbeck process in the log of the variance,

$$
d \ln (V)-\left[\alpha^{\prime}-\beta^{\prime} \ln (V)\right] d t+\alpha_{v} d Z_{v}
$$

used by Hull and White (1987) and Scott (1987), and which is the continuous-time limit of Nelson's (1990) EGARCH model. There are two major differences, however. First, the instantaneous variance conditional on no jumps under the former specification can hit a reflecting barrier of zero if $2 \alpha<\sigma_{v}^{2}$ whereas under (2) it can never reach zero (although it can get arbitrarily close). Second, the volatility of variance increases at a lower power of variance under (1) than under (2). Whether these differences are empirically important is an open issue.

The major advantages to the former specification for the variance process are twofold. First, the model can allow for systematic volatility risk, whereas Hull and White (1987) had to impose the assumption of nonsystematic volatility risk to generate a tractable option pricing model. The issue is that if the true process is given by (1), then in a representative agent production economy the "risk-neutral" processes used in pricing options that incorporate the appropriate compensation for jump risk and volatility risk are given by

$$
\begin{aligned}
& d S / S-\left(b-\lambda \cdot \bar{k}^{*}\right) d t+\sqrt{V} d Z^{*}+k^{*} d q^{*} \\
& d V-\left[\alpha-\beta V+\Phi_{v}(V)\right] d t+a_{v} \sqrt{V} d Z_{v}^{*} \\
& \operatorname{Cov}\left(d Z^{*}, d Z_{v}^{*}\right)=\rho d t \\
& \operatorname{Prob}\left(d q^{*}-1\right)-\lambda \cdot d t, k-\left(\bar{k}^{*}, \operatorname{Var}\left(\bar{k}^{*}\right)\right)
\end{aligned}
$$

'See Bates (1988b). 
where $b$ is the continuously compounded domestic/for eign interest differential, and starred variables represent the risk-adjusted versions of the true variables, taking into account the pricing of jump risk and volatility risk. In particular:

$$
\begin{aligned}
& \Phi_{v}=\operatorname{Cov}\left(d V, \frac{d J_{w}}{J_{w}}\right) \\
& \lambda^{*}-\lambda E\left(1+\frac{\Delta J_{w}}{J_{w}}\right) \\
& \bar{k}^{*}-\bar{k}+\frac{\operatorname{Cov}\left(k, \Delta J_{w} / J_{w}\right)}{E\left[1+\Delta J_{w} / J_{w}\right]}
\end{aligned}
$$

where $J_{w}$ is the marginal utility of dollar wealth of the world-average representative investor, $\Delta J_{w} / J_{n}$ is the random percentage jump conditional on a jump occurring, and $d J_{w} / J_{w}$ is the percentage shock in the absence of jumps. ${ }^{\text {.g }}$ As usual, isoelastic utility is a convenient assumption to make at this stage, and implies that the volatility risk premium $\Phi_{\mathrm{v}}=\mathrm{f}(V)$ depends only on $V, \ln \left(1+k^{*}\right)$ is normally distributed with the same variance $\delta^{2}$ as the actual jumps, and $\lambda^{*}$ and $\bar{k}^{*}$ are constant. ${ }^{9}$

A no-arbitrage constraint on the functional form of the volatility risk premium $\Phi_{v}(V)$ is that

\footnotetext{
'Issues of heterogenous international investors and deviations from purchasing power parity, which would involve including additional state variables for the distribution of wealth across heterogeneous agents. are being ignored here. More precisely, such effects are assumed here to affect only the foreign currency risk premium $\mathrm{E}(\mathrm{dS} / \mathrm{S})-\left(r-r^{*}\right)=\mu-b$, and therefore to have no effect upon options prices. The potential general equilibrium effects of the omitted state variables on interest rates and upon volatility are ruled out by the imposed distributional assumptions. For an illustration of the (limited) general equilibrium impact of investor heterogeneity upon interest rates, see Dumas (1989).
}

The specification of the risk-neutral process depends upon the choice of numeraire. The above specification (3) is the risk-neutral process for $\$ / F C$ to be used in generating dollar-denominated prices of foreign currency options. For foreign-currency denominated options prices it is necessary to use the marginal utility of foreign-currency denominated wealth $J_{w}$ when computing $\Phi_{n} \lambda^{*}$ and $\bar{k}^{*}$. An Ito's lemmabased transformation of variables of the process (3) using $z=S^{\prime \prime}$ is not correct.

The additional restriction that the process for optimally invested wealth follow a geometric stochastic volatility/jump-diffusion process with constant parameters is also required here. 
$\Phi_{v}(0)=0 .{ }^{10}$ This restriction precludes modelling the volatility risk premium as proportional to $\ln (V)$ when the log of volatility follows an Ornstein-Uhlenbeck process, and necessitated Hull and White's (1987) assumption of nonsystematic volatility risk $\left(\Phi_{v}-0\right)$ for analytic tractability. In the case of the square root volatility process, however, the volatility risk premium can plausibly be modelled as proportional to the conditional variance $V_{i}: "$

$$
\Phi_{v}(V)-\xi V \text {. }
$$

The result is that the "risk-neutral" process for the instantaneous conditional variance resembles the true process in form:

$$
\begin{aligned}
d V & -(\alpha-\beta V+\xi V) d t+\sigma_{v} \sqrt{V} d Z_{v}^{*} \\
& =(\alpha-\beta \cdot V) d t+\sigma_{v} \sqrt{V} d Z_{v}^{*} .
\end{aligned}
$$

Note, however, that the steady-state level $\left(\alpha / \beta^{*}\right)$ towards which variance tends to revert implicit in option prices is not the true steady-state level, but rather differs by an amount that depends on the volatility risk premium.

The second major advantage to the square root process for variance is that the process generates an analytically tractable method of pricing options without sacrificing accuracy or

${ }^{10}$ See Ingersoll (1987, Chapter 18) for a discussion of a similar issue with regard to the term structure of interest rates.

"Strict linearity of the volatility risk premium can be supported under log utility when exchange rate volatility and market risk have a common component of a particular form. The linear specification will not typically emerge under more general preferences (e.g., time-separable power utility) and should be viewed for such preferences as an approximation to the true functional form. Cox, Ingersoll, and Ross (1984) use a similar approximation when modelling the risk premium on interest rates. 
requiring undesirable restrictions (such as $\rho=0$ ) on parameter values. ${ }^{12}$ European options that can be exercised only at maturity are priced as the expected value of their terminal payoffs under the "risk-neutral" probability measure:

$$
\begin{aligned}
c & -e^{-r T} E^{*} \max \left(S_{T}-X, 0\right) \\
& -e^{-r T}\left[\int_{X}^{-} S_{T} p^{*}\left(S_{T}\right) d S_{T}-X \int_{X}^{-} p^{-}\left(S_{T}\right) d S_{T}\right] \\
& =e^{-r T}\left(F P_{1}-X P_{2}\right)
\end{aligned}
$$

where

$$
\begin{aligned}
& E^{*} \text { is the expectation with respect to the risk-neutral probability measure; } \\
& F=\mathrm{E}^{*}\left(S_{T}\right)=S_{T} e^{b T} \text { is the forward price on foreign currency; } \\
& P_{2}=\operatorname{Prob}^{*}\left(S_{T}>X\right) \text { is one minus the risk-neutral distribution function; and } \\
& P_{1}=\int_{X}\left[S_{T} / \mathrm{E}^{*}\left(S_{T}\right)\right] P^{*}\left(S_{T}\right) d S_{T} \text { is also a probability (since the integrand is } \\
& \text { nonnegative, and the integral over }[0, \infty) \text { is one). }
\end{aligned}
$$

For instance, the Garman-Kohlhagen version of the Black-Scholes formula for foreign currency options under the assumption of constant-volatility geometric Brownian motion for the exchange rate is

$$
c=e^{-r T}\left[F N\left(d_{1}\right)-X N\left(d_{2}\right)\right]
$$

where

$$
d_{j}=\left[\ln (F / X)+1 / 3 \sigma^{2} T\right] / \alpha T \text {, and } d_{2}=d_{j}-\sigma \sqrt{ } T^{13}
$$

${ }^{12}$ Hull and White (1988) give an analytical approximation for pricing European options on the square root stochastic volatility process that is quite accurate for small (and plausible) values of $\sigma_{v}$. A jumpdiffusion extension of this approximation was developed and used as an independent check on the option pricing formulas given below.

${ }^{12}$ The foreign-currency options traded on the Philadelphia Stock Exchange trade up through the Friday preceding the third Wednesday of the contract month -- that Wednesday being the delivery date for the underlying currency. Given the delay between the last trading day and the delivery day, the correct Black-Scholes formula for PHLX European calls is 
The European option evaluation problem is to evaluate $P_{J}$ and $P_{2}$ under the distributional assumptions embedded in the risk-neutral probability measure. The difficulty is that the cumulative distribution function for most distributions is messy and, in many cases, we do not have any idea of what it looks like. Even the Black-Scholes model has a distribution related to the error function, which is nontrivial to evaluate. When it comes to stochastic volatility models, the distribution function is unknown. The difficulty in evaluating $P_{J}$ and $P_{2}$ is responsible for a bias towards series solutions for pricing options. ${ }^{14}$

Heston (1993) pointed out that it is much easier to solve for the moment generating functions associated with $P_{1}$ and $P_{2}$. Essentially, one can view the moment generating function as a contingent claim to be solved using the standard contingent claims' partial differential equation under relatively easy boundary conditions; details are in Appendix I. (The P's also solve the equation -- subject, however, to discontinuous boundary conditions that preclude easy solutions.) Once one has the moment generating function, there exist fast numerical procedures for evaluating $P_{1}$ and $P_{2}$. The resulting moment generating functions of $\ln \left(S_{Y} / S_{0}\right)$ for the two probabilities $P_{f}$ and $P_{2}$ when exchange rates follow a combination stochastic volatility/jump-diffusion process are given by

$$
c-e^{-r\left(T+\Delta t_{1}\right)}\left[F N\left(d_{1}\right)-X N\left(d_{2}\right)\right]
$$

where

$T$ is the time until the Friday preceding the third Wednesday; $\Delta t_{i}=5 / 365$ is the time between the last trading day and the delivery day; $F$ is the forward price for currency delivered on the third Wednesday; $d_{1}=\left[\ln (F / X)+1 / 2 \sigma^{2} T\right] / \sigma \sqrt{ } T$, and $d_{1}=d_{1}-\sigma \sqrt{ } T$.

${ }^{14}$ Examples include Cox and Rubinstein's (1985) constant elasticity of variance option pricing model, Merton's (1976) formula for options on jump-diffusions processes and Hull and White's (1988) analytic approximation for options on square root stochastic volatility processes. 


$$
\begin{aligned}
& F_{j}(\Phi \mid V, T) \cdot E^{*}\left[e^{\left.\bullet \ln / s_{\gamma} / s_{0}\right)} \mid P_{j}\right] \quad(j-1,2) \\
& -\exp \left\{C_{j}(T ; \Phi)+D_{j}(T ; \Phi) V+\lambda^{*} T\left[\left(1+\bar{k}^{*}\right) e^{\Delta s\left(H, \Phi+\psi^{2} \theta^{2}\right)}-1\right]\right\}
\end{aligned}
$$

where

$$
\begin{aligned}
& C_{j}(T ; \Phi)-\left(b-\lambda^{*} \bar{k}^{*}\right) \Phi T-\frac{\alpha T}{\sigma_{\nu}^{2}}\left(\rho \sigma_{\nu} \Phi-\beta_{j}-\gamma_{j}\right) \\
& -\frac{2 \alpha}{\sigma_{v}^{2}} \ln \left[1+1 / 2\left(\rho \sigma_{v} \Phi-\beta_{j}-\gamma_{j}\right) \frac{1-e^{\gamma_{j}}}{\gamma_{j}}\right] \text {, } \\
& D_{j}(T ; \Phi)--2 \frac{\mu_{j} \Phi+1 / 2 \Phi^{2}}{\rho \sigma_{v} \Phi-\beta_{j}+\gamma_{j} \frac{1+e^{\gamma / T}}{1-e^{\gamma / T}}}, \\
& \gamma_{j}-\sqrt{\left(\rho \sigma_{v} \Phi-\beta_{j}\right)^{2}-2 \sigma_{v}^{2}\left(\mu_{j} \Phi+1 / 2 \Phi^{2}\right)}, \\
& \mu_{1}=+1 / 2, \mu_{2}=-1 / 2, \beta_{1}=\beta^{*}-\rho \sigma_{v} \text {, and } \beta_{2}=\beta^{*} \text {. }
\end{aligned}
$$

Given the above solutions for the moment generating functions, the relevant tail probabilities $P_{j}\left(\Phi \mid S_{0}, T\right)=\operatorname{Prob}^{*}\left(S_{\tau} e^{b_{s_{1}}}>X \mid F_{j}\right)$ for evaluating PHLX options can be determined numerically via Fourier inversion of the complex-valued characteristic function $F_{j}\left(i \Phi \mid S_{0,} T\right)$ :

$$
\operatorname{Prob}^{*}\left(S_{T} e^{b \Delta r_{1}}>X \mid F_{j}\right)-\frac{1}{2}+\frac{1}{2 \pi} \int_{--}^{-} \frac{F_{j}(i \Phi) e^{-i \phi_{x}}}{i \Phi} d \Phi
$$

where $x=\ln \left(X e^{-\Delta \omega_{1}} / S_{0}\right)$ and $\Delta \mathrm{l}_{1}=5 / 365$ is the lag between the last trading day and the delivery day on PHLX options. By the properties of characteristic functions, ${ }^{15}$ the integral is real-valued and the probability can also be written as

\footnotetext{
${ }^{15}$ The real part of $F(i \Phi)$ is an even function of $\Phi$, the imaginary part is an odd function (Feller (1971), v.II, p.499).
} 


$$
\operatorname{Prob}^{\prime}\left(S_{\tau} e^{b \Delta \Delta_{1}}>X \mid F_{j}\right)-\frac{1}{2}+\frac{1}{\pi} \int_{0}^{-} \frac{\operatorname{Imag}\left[F_{j}(i \Phi) e^{-1{ }^{-x}}\right]}{\Phi} d \Phi
$$

The probability density function of $\ln \left(S_{\tau} / S_{0}\right)$ under the risk-neutral probability measurc has a similar form:

$$
\begin{aligned}
p^{*}(z) & -\frac{1}{2 \pi} \int_{--}^{-} F_{2}(i \Phi) e^{-i \varphi z} d \Phi \\
& -\frac{1}{\pi} \int_{0}^{-} \operatorname{Real}\left[F_{2}(i \Phi) e^{-i \oplus z}\right] d \Phi .
\end{aligned}
$$

where $z=\ln \left(S_{\tau} / S_{0}\right)$.

The integrals in (14) or (15) can be evaluated efficiently via Gaussian quadrature. A GaussKronrod rule based upon IMSL subroutine DQDNG that evaluated $F(i \Phi)$ at up to 87 points over a truncated domain was found to be accurate to $10^{-8}$ times the spot exchange rate ( 4 orders of magnitude less than the minimum price change), except for extreme and implausible jump parameters. ${ }^{10}$ Since pricing call and put options of a common maturity require the same values of $F_{\lambda}(i \Phi)$ regardless of the strike price/spot price ratio, enormous efficiency gains can be realized by evaluating such all options simultaneously. ${ }^{17}$

${ }^{10}$ Extreme values of $\bar{k}$ (e.g., $30,000 \%$ ) made $F(i \Phi)$ highiy oscillatory, and reduced accuracy to $10^{\text {s }}$ $\times S$, which is still an order of magnitude less than the minimum tick size. Accuracy was measured by comparing option prices with those evaluated to $10^{-10}$ accuracy using IMSL's adaptive Gaussian quadrature subroutine DQDAGI for integrating functions over a semi-infinite domain.

${ }^{17}$ An earlier version of this paper used a Fast Fourier Transform (FFT) approach, which intrinsically involves trapezoidal integration. However, the relative efficiency of Gaussian quadrature in requiring fewer function evaluations appears to dominate the computational advantages with regard to multiplication of the FFT. 
The above procedure gives the price of a European option as a function of state variables and parameters:

$$
c(S, V, T ; X, \theta)-e^{-r\left(T \cdot \Delta t_{2}\right)}\left[F P_{1}-X P_{2}\right]
$$

for $\theta=\left\langle\lambda^{*}, \bar{k}^{*}, \delta, \alpha, \beta^{*}, a_{v}, \rho\right\rangle$. However, since the PHLX options on foreign currency are American in nature, it is in principle important to take into account the extra value accruing from the ability to exercise the options prior to maturity. This study uses the constant-volatility analytic approximation from Bates (1991) for jump-diffusions, modified for the 4 business day lag between early exercise of a PHLX option and delivery of the underlying currency:

$$
C(S, V, T ; X)= \begin{cases}c(S, V, T ; X)+X A_{2}\left(\frac{S / X}{y_{c}^{*}}\right)^{g_{2}} \text { for } S / X<y_{c}^{*} \\ e^{-r \Delta y_{3}}\left(S e^{b \Delta L_{2}}-X\right) & \text { for } S / X \geq y_{c}^{*}\end{cases}
$$

where

$\Delta s_{2}$ is the delivery lag (4/365 if Monday, $6 / 365$ otherwise);

$A_{2}=e^{-v_{2} s_{2}}\left(y_{c}^{*} e^{b \Delta_{2}}-1\right)-c\left(y_{c}^{*}, \bar{v}, T, 1\right)$;

$q_{2}$ is the positive root to

$$
1 / 2 \bar{V} q^{2}+\left(b-\lambda \cdot \bar{k}^{*}-1 / 2 \bar{V}\right) q-\frac{r}{1-e^{-r T}}+\lambda \cdot\left[\left(1+\bar{k}^{*}\right)^{q} e^{1 / 2 q(q-1) d+}-1\right]=0,
$$

$\vec{V}$ is the expected average variance over the lifetime of the option conditional on no jumps:

$$
\bar{V}=\frac{1}{T} E \int_{0}^{T} V_{1} d t-\frac{\alpha}{\beta^{*}}+\left(V_{0}-\frac{\alpha}{\beta^{*}}\right) \frac{1-e^{-\beta^{*} T}}{\beta^{*} T}
$$

and the critical spot price/exercise price ratio $y_{c}^{*} \geq 1$ above which the call is exercised immediately is given implicitly by 


$$
e^{-r \Delta s_{2}}\left(y_{c}^{*}-1\right)-c\left(y_{c}^{*}, \bar{V}, T ; 1\right)+\frac{y_{c}^{*}}{q_{2}}\left[e^{(b-r) \Delta \Delta_{2}}-c_{s}\left(y_{c}^{*}, \bar{V}, T ; 1\right)\right] .
$$

A similar approximation exists for the put early-exercise premium.

Strictly speaking, the approximation for the early-exercise premium was derived for constantvolatility jump-diffusions. A comparison with option prices computed via finite-difference methods revealed a maximal approximation error of around 0.01 a/DM for 6-month in-the-money put options. The approximation error is substantially smaller for shorter-maturity put options and for puts with different strike prices, and is negligible for call options of all maturities considered (given U.S. interest rates substantially higher than German rates over most of the data sample). Given that the data set considered below consists predominantly of short-maturity out-of-the-money options and contains relatively few in-the-money puts, the approximation error in the early-exercise premium was not felt to be of major concern. 


\section{Estimation}

\section{A. Data}

Transactions data for Deutschemark foreign currency options were obtained for January 1984 to June 1991 from the Philadelphia Stock Exchange." Prior to September 26, 1987, only options maturing in March, June, September or December were traded, with contract specifications geared to the corresponding IMM foreign currency futures contracts in size $(62,500$ Deutschemarks, half the size of the IMM futures contracts) and maturity (third Wednesday of the contract month). Trading in contracts maturing the nearest other two months began on September 27, 1987. The options are American, and could be exercised at any time up to and including the Saturday preceding the third Wednesday of the contract month.

Roughly $1 \%$ of the records mildly violated early-exercise constraints, presumably due to measurement error in matching up the underlying futures price. Since discarding these data would bias upward average in-the-money option prices, influencing the implicit parameter estimation, these data were retained. There was also no attempt to weed out thinly traded option contracts, apart from the fact that those contracts by their nature received a low weighting in the regressions. A few obviously erroneous data $(0.1 \%$ of the total data) were discarded.

Only a subset of the full data set was used in this study. First, only trades on Wednesdays were considered, yielding a weekly frequency panel data set. Daily sampling would place extreme demands on computer memory and time, and would involve issues of modelling day-of-the-week volatility effects that I do not wish to explore at this time. Second, only morning trades (9-12 EST)

\footnotetext{
${ }^{12}$ Data were also available for options on British pounds, Canadian dollars, Japanese yen and Swiss franes, and will be examined at a later stage. Options on French francs, though also available, are too thinly traded to merit scrutiny.
} 
were considered -- a tradeoff between shortening the interval for greater synchronicity, and lengthening it to get more observations. ${ }^{\text {I9 }}$ Third, only options with March/June/September/ December maturities and with 6 months or less to maturity were used -- for a maximum of two option maturities per day. The resulting data set consists of 19,689 transactions $(11,952$ calls; 7,737 puts) on 372 Wednesday mornings over January 4, 1984 - June 19, 1991; an average of 53 trades per morning. Not all Wednesdays are included, owing to data collection problems at the Philadelphia Stock Exchange during February 1985, November 1985, and September 1988.

Other data needed in pricing foreign currency options include the underlying asset price, a risk-free discount rate, and the domestic/foreign interest rate differential. Transactions prices for IMM foreign currency futures were obtained from the Chicago Mercantile Exchange, and the nearest preceding futures price of comparable or shorter maturity was used as the underlying asset price -- provided the lapsed time was less than 5 minutes. Otherwise, the option record was discarded. The futures data were of higher quality than the Telerate time-stamped spot exchange rate quotes provided by the Philadelphia Stock Exchange, which were occasionally egregiously wrong. ${ }^{30}$ Daily 3 -month Treasury bill yields were used for the risk-free discount rate. The daily domestic/foreign interest rate differential was inferred from synchronously recorded spot rates and 1- and 3-month forward rates, using covered interest parity and adjusting for weekend and end-ofmonth effects on the maturity of the forward contract.

${ }^{19} 50 \%$ of the daily trades over 1984-1991 took place between 9 and 12. The greatest activity was between 9 and 10:30, when U.S. and European markets were open simultaneously.

${ }^{20}$ Another oddity of the Philadelphia Stock Exchange data base is that prior to September 28 , 1984, every record appears twice. The duplicate data were discarded. 


\section{B. Unconstrained Implicit Parameter Estimation}

Implicit parameters were initially estimated via nonlinear equal-weighted least squares on the panel data set of call and put prices for all observed strike prices and (quarterly cycle) maturities on Wednesday mornings over January 4, 1984 - June 19, 1991:

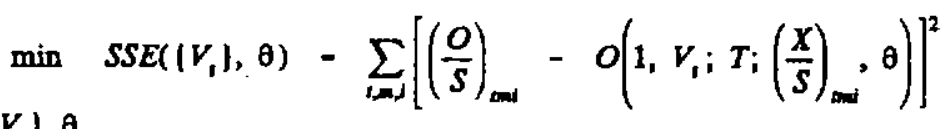

$$
\begin{aligned}
& (V,), \theta
\end{aligned}
$$

where

$r$ is an index over Wednesday mornings within the specified period;

$m$ is an index over at most 2 maturities on a given Wednesday morning;

$i$ is an index over transactions (calls and puts of assorted strike prices) for a given day and maturity;

$(O / S)_{m}$ is the observed call or put option price/spot price ratio for a given transaction, using an implicit spot from a synchronous futures transaction;

$O(\cdot)$ is the theoretical American option price given the contractual terms of the option (call/put, time to maturity $T_{\infty n}$ strike price/spot price ratio $(X / S)_{m}$ ) and given that day's instantaneous variance $V_{1}$, other parameters $\theta$ of the model, and that day's interest rate $r_{1}$ and interest differential $b_{1}=r_{1}-r_{r}^{*}$

For the full stochastic volatility/jump-diffusion model, $\theta$ was the set of jump and stochastic volatility parameters:

$$
\theta=\left\langle\lambda^{*}, \bar{k}^{*}, \delta, \alpha, \beta^{*}, \sigma_{v} \rho\right\rangle
$$

The following subcases of the general model were also estimated: 
1. "Black-Scholes" model (American option version), $\left\{V_{1}\right\}$ with the same implicit volatility for all maturities on a given day

2. Deterministic volatility model, allowing daily an downward or upward sloping term structure of implicit volatilities (depending on whether $\left.V_{1} \gtrless \alpha / \beta^{*}\right)$

3. Stochastic volatility model $\left\{V_{1}\right\}, \alpha, \beta^{*}, \sigma_{n} \rho$

4. Stochastic volatility/jump-diffusion model $\{V\}, \alpha, \beta^{*}$

Note that the average Wednesday morning realizations of the instantaneous variance $\left\{V_{1}\right\}$ must also be estimated. Intradaily movements in instantaneous variance were ignored in the estimation procedure.

Two points should be made regarding the above regression. First, the usual time series objection to estimating the set of instantaneous variance realizations $\left\{V_{1}\right\}$ and thereby having an additional free parameter for each new day does not arise when options are used. In essence, the daily realization of $V$, is observable from option prices, whereas it is not under time series estimation.

Second, the restriction that the process $\left\{V_{1}\right\}$ actually be drawn from its postulated distribution .- in particular, that volatility follow a diffusion .. has not been imposed at this stage. Non-zero parameter estimates are being generated cross-sectionally off the observed moneyness and maturity biases of the option prices relative to the benchmark Black-Scholes model, and not off the time series properties of $\left\{V_{l}\right\}$. The regression is in essence a "method of moments" estimator in which transformations of the moments .. the option prices -- are observed with almost no noise. 
The separate case in which $V$, estimates are constrained by the postulated diffusion will be examined below.

Parameters were estimated using GQOPT quadratic hill-climbing software, methods GRADX and DFP, with multiple starting values. First and second derivatives of the loss function were computed numerically, coded to eliminate irrelevant computations. ${ }^{21}$ Estimates of implicit parameters on the full data set took between 8 hours and 3 days on a dedicated Hewlett-Packard Apollo 720 workstation, depending upon which model was used.

For full sample estimation over 1984-91, allowing for stochastic volatility and for jumps reduced standard errors only by about $0.006 \%$ of the spot rate relative to the ad hoc Black-Scholes procedure of estimating a different implicit volatility for every day in the sample (see Table 1 ). With an average exchange rate around $50 \mathrm{e} / \mathrm{DM}$ over the sample, this represents a reduction in standard errors of about $0.003 \& / D M$-- less than $1 / 2$ price tick. Over half of this improvement was attributable to relaxing the daily constraint of a flat term structure of volatilities, and instead allowing for a monotonically decreasing or increasing term structure (depending on whether $V, \gtrless$ $\left.\alpha / \beta^{*}\right)$ under the deterministic volatility model. Reduction of remaining moneyness and maturity biases using the stochastic volatility and stochastic volatility/jump-diffusion models reduced standard errors by a further $1 / 10$ of a price tick. Allowing for jumps created a statistically but not economically significant increase in the model's ability to match option prices relative to the stochastic volatility model.

\footnotetext{
${ }^{21}$ In particular, $\partial S S E / \partial V_{n} \partial^{2} S S E / \partial\left(V_{V}\right)^{2}$, and $\partial^{2} S S E /\left(\partial V_{1} \partial \theta_{i}\right)$ were computed numerically using date-t options only, while $\partial^{2} S S E /\left(\partial V_{s} \partial V_{t}\right)=0$ for $\mathrm{s} \neq \mathrm{t}$.
} 
Estimates of implicit parameters for two-year subsamples revealed substantial and statistically significant subsample instability. Root mean squared error for the stochastic volatility and stochastic volatility/jump-diffusion models fell $0.06 \%$ of the spot price ( $1 / 4$ price tick) relative to the full-sample parameters, ending up $0.012 \%$ (1/2 price tick) below the ad hoc "Black-Scholes" estimates. Three-quarters of the improvement relative to Black-Scholes was again attributable to a better modelling of the term structure of implicit volatilities. The stochastic volatility model's ability to explain residual moneyness and maturity biases was of secondary importance, reducing standard errors only by a further $1 / 8$ price tick. The combined stochastic volatility/jump-diffusion model had a substantially identical performance in subsamples to the stochastic volatility model. Allowing for jumps increased explanatory power during the strong-dollar early years of the sample - particularly 1984-85.

Full-sample estimation of the general model yields a high-frequency low-amplitude jump component that is observationally equivalent to geometric Brownian motion. ${ }^{22}$ In effect, a geometric Brownian motion/stochastic volatility process is being estimated. The instantaneous variance process consists of a constant plus a mean-reverting component:

$$
\operatorname{Var}(d S / S)=\mathrm{V}_{\text {jump }}+\mathrm{V}_{1}
$$

where $V_{j \mathrm{mp}}=\lambda^{*}\left\{\left[\ln \left(1+\bar{k}^{*}\right)-1 / \delta \delta^{2}\right]^{2}+\delta^{2}\right\}$, the variance attributable to jumps, was estimated at $(6.6 \%)^{2}$ per year. The mean-reverting component $V_{1}$ under the SVJD model had generally plausible parameters: a steady-state level of $(13.4 \%)^{2}$ per year, a half-life to volatility shocks of 7.5 months. The estimated mean reversion reflected the tendency of the term structure of implicit volatilities to be upward sloping for low short-term volatilities, and to be inverted for high values. Parameters

\footnotetext{
${ }^{2}$ Inspection of the moment generating function (9) for small values of $\delta$ reveals the equivalence of low-amplitude jumps and geometric Brownian motion, except at intradaily frequencies.
} 
for the stochastic volatility model were comparable. The estimated instantaneous conditional variances were indistinguishable for both models (Figure 1). However, the sample path for $\operatorname{Var}(d S / S)$ estimated under the SVJD model involved a reflection off the minimum value of $V_{\text {jump. }}$ whereas the path estimated under the $S V$ model never approached the reflecting barrier at $V_{1}=0$.

Full-sample parameter estimates from the SVJD model indicate a distribution slightly more positively skewed than the lognormal distribution underlying the Black-Scholes and deterministic volatility option pricing models (Figure 2), at all but extremely short horizons. Implicit skewness did not appear to be stable over time, however, with positive implicit skewness in the first half of the sample relative to the lognormal distribution, and predominantly negative implicit skewness in the second half. A substantial volatility of variance implied moderate leptokurtosis at longer horizons relative to the lognormal distribution. The excess kurtosis is present in all biannual subsamples. No evidence of substantial excess kurtosis for daily or weekly holding horizons was found, contrary to the evidence from time series studies cited in Bollerslev, Chou, and Kroner (1992). Instead, the profile of kurtosis across maturities was almost entirely driven by the stochastic volatility process, with a direct rather than inverse relationship evident.

Decomposition of the residuals of the stochastic volatility/jump-diffusion model estimated over 1984-1991 in Table III reveals that the model tended to overprice out-of-the-money call and put options of all maturities and underprice in-the-money put options of all maturities. At first glance, it appears surprising that the pricing errors for calls and puts of comparable strike prices should diverge in sign, given that put-call parity (for the European portion of the option prices) implies that the pricing errors should be comparable in sign and magnitude. Further scrutiny of the residuals reveals that the divergent moneyness biases for calls versus puts was attributable to the parameter instability noted above, combined with the fact that calls were relatively heavily traded 
in the first half of the 1984-91 period while puts were more heavily traded in the second half.

\section{Consistency with the time series properties of implicit volatilities}

As noted by Cox, Ingersoll and Ross (1984), the transition density of $y=2 c V_{t+\Delta,}$ conditional on $V_{1}$ is noncentral chi-squared $\chi^{2}\left(4 \alpha / \sigma_{w}^{2} 2 c V, e^{-\beta \Delta}\right)$, where $c^{-1}=1 / 2 \sigma_{v}^{2}\left(1-e^{-\beta \Delta t}\right) / \beta$ and $\beta$ is the actual rate of mean reversion of the volatility process (as distinct from the risk-adjusted parameter $\beta^{*}$ implicit in option prices):

$$
p\left(y \mid V_{1}\right)=\frac{e^{-1 h(y+\Lambda)} y^{1 / 3 v-1}}{2^{1 / v}} \sum_{j=0}^{-} \frac{(1 / 4 y \Lambda)^{j}}{\Gamma(1 / 2 v+j) j l}
$$

where $v=4 \alpha / \sigma_{v}^{2} \Lambda \equiv 2 c V, e^{-\beta \Delta}$, and $\Gamma(\cdot)$ is the gamma function. However, the non-central chisquared density function has infinite value at $2 c V_{t+\Delta}=0$ when the reflecting barrier is attainable $(1 / 2 v<1)$, yielding nonsensical results when the sample path $\left\{V_{t}\right\}$ is among the parameters to be estimated. Consequently, the applications below use the transition density of the monotonic transformation $\ln \left(V_{t+\Delta}\right)$, which has finite density everywhere:

$$
p\left(\ln V_{t \cdot \Delta t} \mid V_{1}\right)-\frac{e^{-1 / n\left(e^{2}+A\right)}\left(e^{x}\right)^{1 / k v}}{2^{1 / 4 v}} \sum_{j=0}^{-} \frac{\left(1 / 4 e^{2} \Lambda\right)^{j}}{\Gamma(1 / 2 v+j) j \mid}
$$

where $\mathrm{e}^{x}=2 c V_{t+\Delta r}$

Maximum likelihood estimates of the parameters $\left\{\alpha, \beta, \sigma_{v}\right\}$ estimated from the time series of implicit instantaneous conditional volatilities $\left\{V_{1}\right\}$ diverge substantially from the parameters $\{\alpha$, $\beta^{*}, \sigma_{v}$ \} estimated cross-sectionally from option prices, as is shown in Table IV. In particular, the volatility of variance $\sigma_{v}$ implicit in option prices is substantially higher than the supposedly identical parameter estimated off the time series properties of $\left\{V_{1}\right\}$. The parameters $\alpha$ and $\beta$ affecting the 
drift are estimated with less precision; nevertheless, there is a significant deviation in estimated $\alpha$ 's.

Given measurement error in option prices, however, the above two-step estimation procedure does not constitute a formal test of the hypothesis of identical $\left\{\alpha, \sigma_{v}\right\}$ parameters for option prices and time series. Under the assumptions that the cross-sectional measurement error in option prices is homoskedastic Gaussian white noise $\mathrm{e}^{23}$ and is independent of volatility realizations, the appropriate loss function for testing hypotheses is

$$
L\left(\left\{V_{1}\right\}, \theta, \beta\right)=L_{\text {opions }}+L_{\{\eta},
$$

where

$L_{\text {opdions }}=1 / 2 N O B S+1 / 2 N O B S \ln \left[2 \pi \operatorname{SSE}\left(\left\{V_{\}}\right\}, \theta\right)\right]$ is a function of the sum of squared and

$$
\text { errors in option prices from equation (21), }
$$

$L_{i n}=\Sigma_{i} \ln p\left(\ln \left(2 c V_{1}\right) \mid \alpha, \beta, \sigma_{v} ; V_{t-1}\right)$ is the log-likelihood of an estimated $\left\{V_{t}\right\}$ sample path given $p(\cdot)$ from equation (23).

The joint hypothesis of identical $\left\{\alpha, \sigma_{v}\right\}$ parameters for options and time series was tested using a likelihood ratio test:

$$
\begin{aligned}
& \text { Unconstrained parameter estimates: }\left\langle\left\{\left\{V_{1}\right\}, \lambda^{*}, \bar{k}^{*}, \delta, \alpha, \beta^{*}, \sigma_{v} \rho\right\}_{\text {opiouse }}\left\{\alpha, \beta, \sigma_{v}\right\}_{\text {time erie }}>\right. \\
& \text { Constrained parameter estimates: }\left\langle\left\{\left\{V_{1}\right\}, \lambda^{*}, \bar{k}^{*}, \delta, \alpha, \beta, \beta^{*}, \sigma_{v}, \rho\right\}_{\text {optiona e e time erenes }}>\right.
\end{aligned}
$$

\footnotetext{
${ }^{n}$ The assumption that measurement error is homoskedastic regardless of strike price, maturity, and whether the option is a call or a put is clearly a strong and implausible assumption. However, the parameter estimates are consistent under the null hypothesis of correct model specification. Increasing efficiency by adjusting for heteroskedastic measurement error would just increase the already substantial weight given to options prices relative to time series observations, and is unikely to change the conclusions below. Serial correlation in measurement errors is a more relevant concern - and more difficult to resolve given the varying maturity structure of the options data.
} 
Table $V$ reports the results of unconstrained versus constrained estimation for the stochastic volatility (SV) and stochastic volatility/jump-diffusion (SVJD) models. Constraining the volatility process brought the volatility of variance parameter $\sigma_{v}$ more in line with the time series behavior of $\left\{V_{1}\right\}$, and smoothed somewhat the estimated sample path of $\left\{V_{1}\right\}$. In fact, constrained estimation actually increased the joint log-likelihood of the SVJD model, given that the estimated unconstrained $\left\{V_{\}}\right\}$sample path was highly implausible. Nevertheless, both the SV and SVJD models are internally inconsistent. The constraint of identical $\left\{\alpha, \sigma_{v}\right\}$ parameters in the options and resulting $\left\{V_{t}\right\}$ time series data for the SV model is strongly rejected, based on two criteria:

1) the worsening of the joint $\log$-likelihood $\left(110,308\right.$ versus $110,369 \ldots$-. -value $\left.<10^{-16}\right)$;

2) the inconsistency of the constrained $\left\{V_{1}\right\}$ implicit parameters $\left\{\alpha, \sigma_{v}\right\}$ and the constrained sample path $\{V\}$ (log-likelihood 97 versus $158 \quad$.. P-value $<10^{-16}$ ).

The latter criterion also yields rejection of the SVJD model, at a P-value less than $10^{-16}$. A comparison of the constrained SV and SVJD models indicates that the hypothesis of no jumps cannot be rejected.

The rejections are predominantly attributable to inconsistencies in the volatility of variance parameter $\sigma_{\mathrm{v}}$. The implausibility of the high $\sigma_{\mathrm{v}}$ implicit in option prices is particularly evident when one compares the unconditional gamma distribution of $\left\{V_{f}\right\}$ implicit in the $S V$ parameter estimates with the sample distribution of $\{V\}$ (Figure 4). A high volatility of variance implies frequent reflections off zero and substantial clustering of implicit instantaneous variances near 0 , contrary to what is observed. The SVID model erroneously predicts an even greater degree of clustering near zero.

Previous studies have argued that the term structure of implicit volatilities is inconsistent with the time series properties of implicit volatilities -- in particular, that the term structure is too 
flat given observed mean reversion of implicit volatilities. ${ }^{24}$ In this model, the term structure of implicit expected average variances for 0-3 month versus 3-6 month options depends upon the parameters $\alpha$ and $\beta^{*}$ :

$$
\bar{V}(T) \cdot \frac{1}{T} E \int_{0}^{T} V_{1} d t=w(T) V_{0}+[1-w(T)] \frac{\alpha}{\beta^{*}}, w(T) \cdot \frac{1-e^{-\beta} \cdot T}{\beta^{*} T} \in[0,1)
$$

Since the expected average variance is roughly the implicit variance from the Black-Scholes model, ${ }^{2 s}$ the issue is equivalent to the issue of whether the $\left\langle\alpha, \beta^{*}\right\rangle$ parameters implicit in option prices are consistent with the $\langle\alpha, \beta\rangle$ parameters derived from the $\operatorname{AR}(1)$ time series properties of implicit variances.

The two sets of parameters do in fact diverge in unconstrained parameter estimation. However, the parameters can in principle diverge because of a volatility risk premium. Furthermore, the standard errors suggest that the divergence is predominantly attributable to diverging $\alpha$ 's rather than to diverging $\beta$ 's. In fact one cannot reject the no volatility risk premium hypothesis $\mathrm{H}_{0}: \beta^{*}=\beta$ at standard significance levels for either the SV or the SVJD model when the $\alpha$ 's (and $\sigma_{v}$ 's) are constrained to be identical. Consequently, it is the mean variance level $\alpha / \beta^{*}$ implicit in option prices (equivalently, the level of long-maturity implicit variances) that is primarily incompatible with the time series properties of implicit variances, rather than the rate of mean reversion towards that average level.

\footnotetext{
${ }^{24}$ Stein (1989) makes this argument with regard to implicit volatilities from S\&P 100 options. while Campa and Chang (1993) make a similar point with regard to interbank foreign currency options.

${ }^{25}$ In principle, there are Jensen's inequality biases relevant to the choice of implicit volatilities versus implicit variances and to the choice of the moneyness of the options used in computing implicit volatilities. These biases do not appear empirically important.
} 


\section{E. Consistency with the time series properties of futures prices}

A further test of the stochastic volatility and stochastic volatility/jump-diffusion models is their consistency or inconsistency with observed realizations of exchange rates and foreign currency futures prices. To examine this, the actual (as opposed to "risk-neutral") futures price process was parameterized as follows:

$$
\begin{aligned}
& d F / F-\left[c_{0}+c_{1}\left(r_{1}-r_{1}^{*}\right)+c_{v} V_{1}-\lambda \bar{k}\right] d t+\sqrt{V_{1}} d Z+k d q \\
& d V-(\alpha-\beta V) d t+\sigma_{v} \sqrt{V} d Z_{v} \\
& \operatorname{Cov}\left(d Z, d Z_{v}\right)-\rho d t \\
& \operatorname{Prob}(d q-1)-\lambda d t, \ln (1+k)-N\left(\ln (1+\bar{k})-1 / 2 \delta^{2}, \delta^{2}\right) .
\end{aligned}
$$

The inclusion of interest differentials in the instantaneous conditional mean nests two alternative hypotheses: that the futures price follows a martingale $\left(c_{0}=c_{1}=c_{v}=0\right)$ and that the underlying spot exchange rate follows a martingale $\left(c_{0}=c_{v}=0, c_{1}=-1\right)$. The inclusion of the instantaneous variance allows for instantaneous "GARCH-in-mean"-type interactions between volatility and the futures price, although higher moments are also affected in discrete time. The resulting probability density of the log-differenced futures price conditional upon instantaneous variance $V_{t}$ is

$$
\begin{aligned}
& p\left[\ln \left(\frac{F_{n}}{F_{n-1}}\right) \mid V_{n-1}\right]-\frac{1}{2 \pi} \int_{-\infty}^{-} \exp \left(C\left(i \Phi, \Delta t_{n}\right)+D\left(i \Phi, \Delta t_{n}\right) V_{n-1}\right. \\
& \left.+\lambda \Delta t_{n}\left[(1+\bar{k}) e^{-\gamma_{2} d x(\theta+i \varphi)}-1\right]-i \Phi \ln \left(F_{n} / F_{n-1}\right)\right] d \Phi \\
& C(\Phi ; \Delta t)-\left[c_{0}+c_{1}\left(r_{t}-r_{i}^{*}\right)-\lambda \bar{k}\right] \Phi \Delta t-\frac{\alpha \Delta t}{\sigma_{v}^{2}}\left(\rho \sigma_{v} \Phi-\beta-\gamma\right) \\
& -\frac{2 \alpha}{\sigma_{v}^{2}} \ln \left[1+1 / 2\left(\rho \sigma_{v} \Phi-\beta-\gamma\right) \frac{1-e^{\gamma \Delta t}}{\gamma}\right]
\end{aligned}
$$




$$
\begin{gathered}
D(\Phi, \Delta t)=\frac{-2\left(c_{\nu}-1 / 2\right) \Phi-\Phi^{2}}{\rho \sigma_{\nu} \Phi-\beta+\gamma \frac{1+e^{\gamma \Delta t}}{1-e^{\gamma \Delta t}}} \\
\gamma-\sqrt{\left(\rho \sigma_{\nu} \Phi-\beta\right)^{2}-2 \sigma_{\nu}^{2}\left[1 / 2 \Phi^{2}+\left(c_{\nu}-1 / 2\right) \Phi\right]} .
\end{gathered}
$$

The log-likelihood function is therefore

$$
L_{(n)}-\sum_{n} \ln p\left[\ln \left(\frac{F_{n}}{F_{n-1}}\right) \mid V_{n-1}\right] .
$$

The stochastic volatility parameters $\left\{\alpha, \sigma_{\mathrm{v}} \rho\right\}$ and the set of instantaneous variance realizations $\left\{V_{1}\right\}$ should theoretically be common to both the option prices and the futures price process. To test for bias in implicit variance forecasts, however, the conditional instantaneous variance was modelled as a linear transform of the instantaneous variance realization implicit in option prices:

$$
V_{1}=c v_{0}+c v_{1} V_{1}^{\text {optians }}, c v_{0} \geq 0
$$

where the coefficients $c v_{o}$ and $c v_{1}$ were estimated. The actual (as opposed to risk-neutral) jump parameters were also estimated, as were the influences of interest differentials and instantaneous volatility. Since option prices provide no direct information about the true rate of variance mean reversion, $\beta$ was initially treated as a free parameter to be estimated.

The futures data were short-maturity ( 0 to 3 months) noon quotes on Wednesdays for which there were options data available. The typical time interval was therefore one week, although there were five occasions in which missing options data resulted in a longer time interval. Weeks in which the maturity of the short-maturity futures contract jumped were excluded. 
Maximum-likelihood estimates of the parameters are presented in Table VIA. As has been found elsewhere, estimates of the conditional mean suggest that it is the spot exchange rate rather than the futures price that follows a martingale, although neither hypothesis can be rejected in this single-currency regression. ${ }^{26}$ No statistically or economically significant jump component was found. The hypothesis that implicit volatilities provide no useful information in forecasting future volatilities was strongly rejected for $\left\{V_{f}^{\text {option }}\right\}$ sample paths estimated from both the stochastic volatility (SV) and stochastic volatility/jump-diffusion (SVJD) models. The hypothesis that the implicit volatility is a linearly unbiased forecast of future volatility (typically over a one-week holding period) was rejected at the $10 \%$ level but not the $5 \%$ level for the SV model, and not at all for the SVJD model.

The inability to reject unbiasedness in the variance forecasts was in part attributable to the existence of a free parameter $\beta$. Consequently, the future price process was re-estimated conditional on the constrained $\left\langle\left\{V_{t}\right\}, \alpha, \beta, \sigma_{n} \rho\right\rangle$ stochastic volatility parameter estimates from Table V -- i.e., taking into account the time series properties of implicit volatilities. The result (Table VIB) is borderline rejections of unbiasedness for the SV and SVJD models. With an average implicit instantaneous variance of $(.13)^{2}$ from the SV model, the average optimal linear transform of $(.12)^{2}$ indicates that implicit instantaneous variances were typically biased upwards relative to subsequent weekly futures price volatility, but not substantially. The bias in variance forecasts is most pronounced in the early part of the 1984-91 sample, and appears to decline somewhat over time.

${ }^{20}$ See Hodrick (1987) and Froot and Thaler (1990) for surveys of the extensive literature on rejections of uncovered interest parity, which is equivalent to rejection of the hypothesis that the futures price follows a martingale. The strongest rejections of uncovered interest parity have been within a multi-currency framework; e.g., Hsieh (1984). 


\section{Section $F$. Consistency with the joint futures and volatility processes}

The above evidence regarding the futures price process was of course based upon two-stage estimation, taking the implicit variance and stochastic volatility parameters as given. It is, however. possible to compute the joint transition density $p\left(\ln F_{t+\Delta,} \ln V_{t+\Delta} \mid F_{t}, V_{t}\right)$ using Fourier inversion techniques; details are in Appendix II. Using the associated log-likelihood function

$$
\left.\ln L_{(F, V)}\left(\mid V_{1}\right), \lambda, \bar{k}, \delta, \alpha, \beta, \sigma_{v}, \delta, c_{0}, c_{1}, c_{v}\right)-\sum_{1} \ln p\left(\ln F_{1}, \ln V_{1} \mid F_{t-1}, V_{t-1}\right)
$$

the hypothesis that the distributions implicit in option prices are consistent with the joint futures and variance series can be examined using the methodology of section IIC. In particular, whether the implicit correlation $\rho$ between futures price innovations and variance innovations is consistent with the time series properties of the two series can be tested.

The parameter estimates in Table VII indicate that futures and implicit volatility innovations typically have a small negative correlation that is not statistically significant, in contrast to the small positive correlation implicit in option prices. The hypothesis of consistent processes is again strongly rejected for the stochastic volatility, given the criteria of unconstrained versus constrained joint options/time series estimation (log-likelihood of 111,225 versus 111298 ; $P$-value $<10^{-16}$ ) and the comparison of the constrained $\{F, \eta\}$ implicit time series parameters $\left\{\alpha, \sigma_{v} \rho\right\}$ with the constrained $\left\{F, \eta\right.$ sample path $\left(1010\right.$ versus 1077: $P$-value $\left.<10^{-16}\right)$. The latter but not the former criterion also leads to rejection of the stochastic volatility/jump-diffusion model.

Parameter estimates indicate that the conditional futures and implicit variance processes are approximately independent: 


$$
p\left(\ln F_{t+\Delta t}, \ln V_{t+\Delta t} \mid F_{t}, V_{t}\right) \sim p\left(\ln F_{t+\Delta t} \mid F_{t}, V_{t}\right) p\left(\ln V_{t+\Delta t} \mid F_{t}, V_{t}\right)
$$

The parameter estimates essentially reflect the variance-constrained estimates of Table IV, combined with the futures process estimated in Table VIB conditional on those variance-constrained estimates. Consequently, the inconsistency of the $\{F, V\}$ parameters implicit in option prices with the time series properties of the futures and implicit variance processes can again be attributed primarily to the implicit variance parameters. There is no evidence in support of the existence of a fat-tailed jump component.

Table VIB also presents stochastic volatility/jump-diffusion parameters estimated under the additional constraints $\lambda=\lambda^{*}, \bar{k}=\bar{k}^{*}$. While in principle the parameters can deviate because of a jump risk premium, calibrations such as in Bates (1991) suggest that it is implausible that the parameters should deviate substantially even when jump risk is fully systematic. Again, no evidence of jumps is found in estimation under these additional constraints.

The absence of a statistically significant jump component in the \$/DM futures price and implicit in the DM option prices over 1984-91 is inconsistent with previous time series studies of the \$/DM exchange rate. Akgiray and Booth (1988) and Jorion (1989) both found statistically significant jump components, while Bollarslev, Chou and Kroner (1992) cite other studies that have found fat-tailed residuals in the \$/DM exchange rate even after adjusting for ARCH/GARCH effects. However, Table VIII indicates that the distribution of the \$/DM exchange rate has changed, with less excess kurtosis for weekly returns over 1984-91 than was the case over 1974-85. Consequently, the distributions implicit in $\mathrm{DM} / \$$ option prices are in fact qualitatively consistent with the time series with respect to the lack of abnormalities. 


\section{Conclusions}

Overall, the Deutschemark options traded on the Philadelphia Stock Exchange appear substantially consistent with the time series properties of the underlying exchange rates. Based on estimation over the fulJ $1984-1991$ period, there is no evidence of a leptokurtic jump component implicit in option prices -- which accords with the absence of such components in weekly futures price changes over that period. Implicit variances are definitely useful in predicting future volatility and are not strongly biased on average, although the hypothesis of unbiased forecasts is rejected.

The major discrepancy between DM options and time series data is that the implicit parameters of the variance process are sharply inconsistent with the time series of implicit variances. The major divergence is in the volatility of variance. This originates in a residual implicit leptokurtosis directly rather than inversely related to option maturity, and therefore cannot be explained away by jumps. The mean variance level implicit in option prices has also been too high relative to the mean of the time series of implicit variances. This latter divergence is primarily relevant for long-term rather than short-term exchange rate volatility forecasting.

A further concern is that the parameters of the time series process are not stable over time. In particular, the steady-state variance level implicit in option prices trended downward over 1984 1991, while implicit skewness changed sign from positive to negative. Of course, the assumption of stability is driven by econometric necessity rather than a priori reasoning. Nevertheless, the evidence of parameter instability suggests that option pricing models based solely on more and more complicated descriptions of the underlying asset price process may ultimately face the same limitations as their corresponding discrete-time ARCH/GARCH counterparts. The research agenda of the future may be to identify those omitted "fundamentals" that are showing up ats parameter shifts in current option pricing models. 
Appendix I: Analytical solutions for moment generating functions

As noted above, the price of a European call can be written as

$$
c=e^{-r T}\left(F P_{1}-X P_{2}\right)
$$

where

$$
\begin{aligned}
& F=E^{*}\left(S_{T}\right)=S_{0} e^{S T} \text { is the forward price on the asset } \\
& P_{z}=\operatorname{Prob}^{*}\left(S_{T}>X\right) \text { is one minus the risk-neutral distribution function } \\
& P_{1}=\int_{\overrightarrow{\mathrm{x}}}\left[S_{T} / \mathrm{E}^{*}\left(S_{T}\right)\right] P^{*}\left(S_{T}\right) d S_{\tau} \text { is also a probability (since the integrand is } \\
& \text { nonnegative, and the integral over }[0, \infty) \text { is one). }
\end{aligned}
$$

The moment generating function $F_{3}\left(\Phi \mid s_{0}\right.$. $\left.V_{0} . T\right)$ associated with the log of the terminal asset price $s_{T}=\ln \left(S_{T}\right)$ under the risk-neutral probability measure,

$$
F_{2}\left(\Phi \mid s_{0}, V_{0}, T\right) \cdot E^{*} e^{\phi s_{\tau}}=e^{-r T} E^{*}\left[e^{r T} e^{* s_{r}}\right]
$$

can be viewed as the current price of a contingent claim that pays off $e^{r t+t r}$ at time $T$. The price of a related contingent claim $G\left(s_{0}, V_{0}, T, \Phi\right)$ that pays off $e^{t /}$ must satisfy the standard condition for contingent clains prices:

$$
E^{*} d G=r G d t
$$

Since $G=e^{-r T} F_{3}$ a simple transformation of variables indicates that $F_{2}$ must solve the related condition $E^{*} d F_{2}=0$. For the stochastic volatility/jump-diffusion process considered above, this implies that $F_{2}$ solves

$$
\begin{gathered}
-F_{T}+\left(b-\lambda \cdot \bar{k}^{*}-1 / 2 V\right) F_{s}+\left(\alpha-\beta^{*} V\right) F_{V} \\
+1 / 2 V\left(F_{s s}+2 \rho \sigma_{v} F_{s V^{*}}+\sigma_{v}^{2} F_{V V}\right)+\lambda^{*} E\left[F\left(s+\gamma^{*}, V\right)-F\right]-0 \\
\gamma^{*}=\ln \left(1+k^{*}\right)-N\left(\ln \left(1+\bar{k}^{*}\right)-1 / 2 \delta^{2}, \delta^{2}\right)
\end{gathered}
$$


subject to the moment generating function boundary condition

$$
\left.F_{2}\right|_{T=0}-e^{\phi z}
$$

A related problem is discussed in Ingersoll (1987, Chapter 18) with regard to pricing bonds. Using a similar methodology, the solution is

$$
\begin{aligned}
& F_{2}\left(\Phi ; s_{0}, V_{0}, T\right)= \\
& \exp \left(\Phi s_{0}+C_{2}(T ; \Phi)+D_{2}(T ; \Phi) V_{0}+\lambda^{*} T\left[\left(1+\vec{k}^{*}\right) e^{1 / 25\left(\Phi^{-}-\right)^{\prime}}-1\right]\right\} .
\end{aligned}
$$

$C_{2}$ and $D_{2}$ solve two ordinary differential equations,

$$
\begin{gathered}
D_{T}=1 / 2 \sigma_{\nu}^{2} D^{2}+\left(\rho \sigma_{\nu} \Phi-\beta^{0}\right) D+1 / 2\left(\Phi^{2}-\Phi\right), D l_{T-0}-0 \\
C_{T}=\left(b-\lambda^{\cdot} \bar{k}^{*}\right) \Phi+\alpha D, C l_{T-0}-0
\end{gathered}
$$

and have the solutions

$$
\begin{gathered}
C_{2}(T ; \Phi)-\left(b-\lambda^{*} \bar{k}^{*}\right) \Phi T-\frac{\alpha T}{\sigma_{\nu}^{2}}\left(\rho \sigma_{\nu} \Phi-\beta^{*}-\gamma_{2}\right) \\
-\frac{2 \alpha}{\sigma_{\nu}^{2}} \ln \left[1+\gamma_{\nu}\left(\rho \sigma_{\nu} \Phi-\beta^{*}-\gamma_{2}\right) \frac{1-e^{\gamma_{2} T}}{\gamma_{2}}\right] \\
D_{2}(T ; \Phi)-\frac{\Phi-\Phi^{2}}{\rho \sigma_{\nu} \Phi-\beta^{*}+\gamma_{2} \frac{1+e^{\gamma_{2} T}}{1-e^{\gamma_{2} T}}} .
\end{gathered}
$$

where

$$
Y_{2}-\sqrt{\left(\rho \sigma_{\nu} \Phi-\beta^{*}\right)^{2}+\sigma_{v}^{2}\left(\Phi-\Phi^{2}\right)}
$$


Solving for $P_{1}=\int_{\mathbf{x}}\left[S_{T} / E^{*}\left(S_{T}\right)\right] P^{*}\left(S_{T}\right) d S_{\mathrm{r}}$ is slightly trickier because it is not the probability function of the risk-neutral probability measure. However,

$$
G-e^{-r T} F P_{1}-S e^{(b-r) T} P_{1}
$$

is the price of a contingent claim that pays off $S_{I}$ at time $T$ conditional on $S_{\tau}>X$, and 0 otherwise. Consequently, $G$ solves the standard condition (A3). Since

$$
\frac{d G}{G}--(b-r) d t+\frac{d S}{S}+\frac{d P}{P}+\left(\frac{d S}{S}\right)\left(\frac{d P}{P}\right)
$$

and $E^{*}(d S / S)=b S d t, P_{1}$ must satisfy

$$
E^{\cdot}\left[d P+\frac{d S}{S} d P\right]-0
$$

Writing $\mathrm{P}_{1}=\mathrm{P}_{1}(s, V, T)$ as a function of the log of the asset price and using (A14) yields the integrodifferential equation

$$
\begin{gathered}
-P_{T}+\left(b-\lambda^{\cdot} \bar{k}^{*}+1 / 2 V\right) P_{s}+\left(\alpha-\beta^{*} V+\rho \sigma_{v} V\right) P_{V} \\
+1 / 2 V\left(P_{s v}+2 \rho \sigma_{v} P_{s V}+\sigma_{v}^{2} P_{V V}\right)+\lambda \cdot E\left\{e^{\gamma}\left[P\left(s+\gamma^{*}, V\right)-P\right]\right\}-0 \\
\gamma^{*}-\ln \left(1+k^{*}\right)-N\left(\ln \left(1+\bar{k}^{*}\right)-1 / 2 \delta^{2}, \delta^{2}\right) .
\end{gathered}
$$

The moment generating function $F_{1}\left(\Phi_{;} s_{0}, V_{0}, T\right)$ underlying $P_{1}=\operatorname{Prob}^{* *}\left(\ln \left(S_{T}\right)>\ln (X)\right)$ must of course also solve the same equation subject to the moment generating function boundary condition (AS). Using the properties of normal distributions, the equation can be written as 


$$
\begin{gathered}
-F_{T}+\left(b-\lambda \cdot \bar{k}^{*}+1 / 2 V\right) F_{s}+\left[\alpha-\left(\beta^{*}-\rho \sigma_{v}\right) V\right] F_{V} \\
+1 / 2 V\left(F_{s s}+2 \rho \sigma_{v} F_{s V}+\sigma_{v}^{2} F_{V V}\right)+\lambda E\left\{\left[F\left(x+\gamma^{*}, V\right)-F\right]\right\}-0 \\
\gamma^{*}-N\left(\ln \left(1+\bar{k}^{*}\right)+1 / 2 \delta^{2}, \delta^{2}\right) .
\end{gathered}
$$

which is of the same form as (A4), with modified parameters. The resulting solution for the moment generating function is

$$
F_{1}\left(\Phi ; s_{0}, T\right)-\exp \left\{\Phi s_{0}+C_{1}(T ; \Phi)+D_{1}(T ; \Phi) V+\lambda \cdot T\left[\left(1+\bar{k}^{*}\right) e^{3 \Delta_{1}(0+\infty)-1}-1\right]\right\}
$$

where

$$
\begin{gathered}
C_{1}(T ; \Phi)-\left(b-\lambda \cdot \bar{k}^{*}\right) \Phi T-\frac{\alpha T}{\sigma_{v}^{2}}\left(\rho \sigma_{v} \Phi-\beta^{*}+\rho \sigma_{v}-\gamma_{1}\right) \\
-\frac{2 \alpha}{\sigma_{v}^{2}} \ln \left[1+\gamma_{2}\left(\rho \sigma_{v} \Phi-\beta^{\nu}+\rho \sigma_{v}-\gamma_{1}\right) \frac{1-e^{\gamma_{1} T}}{\gamma_{1}}\right], \\
D_{1}(T ; \Phi)-\frac{-\Phi-\Phi^{2}}{\rho \sigma_{v} \Phi-\beta^{v}+\rho \sigma_{v}+\gamma_{1} \frac{1+e^{\gamma_{1} T}}{1-e^{\gamma_{1} T}}}
\end{gathered}
$$

and

$$
\gamma_{1}-\sqrt{\left(\rho \sigma_{\nu} \Phi-\beta^{*}+\rho \sigma_{v}\right)^{2}-\sigma_{v}^{2}\left(\Phi+\Phi^{2}\right)} .
$$


Appendix II: Joint transition densities

The generalized joint processes estimated in Section IL.F are of the form

$$
\begin{gathered}
d s=\left[\mu-\lambda \bar{k}+\left(c_{v}-1 / 2\right) V\right] d t+\sqrt{V} d W+\ln (1+k) d q \\
d V=(\alpha-\beta V) d t+\sigma_{v} \sqrt{V} d W_{v}
\end{gathered}
$$

where $s$ is the $\log$ of the asset price, $\operatorname{Cov}\left(d W, d W_{v}\right)=\rho d t$ and $\ln (1+k)$ is normally distributed. The joint moment generating function underlying the transition density $p\left(s_{T}, V_{T} \mid s_{0}, V_{0}\right)$ is

$$
F(\Phi, \psi ; T)=E\left[e^{\Delta s_{\tau} \cdot * v_{\tau}} \mid s_{0}, V_{0}\right],
$$

which solves the partial differential equation

$$
\begin{aligned}
F_{T}- & {\left[\mu-\lambda \vec{k}+\left(c_{v}-1 / 2\right) V\right] F_{z}+(\alpha-\beta V) F_{V} } \\
& +1 / 2 V\left(F_{s s}+2 \rho \sigma_{v} F_{s V}+\sigma_{v}^{2} F_{V V}\right)+\lambda E[F(s+\ln (1+k), V)-F]
\end{aligned}
$$

subject to the boundary condition

$$
F(\Phi, \boldsymbol{\psi} ; 0)-e^{* x_{0} * * v_{0}}
$$

The solution is

$$
F_{j}(\Phi, \psi ; T)=\exp \left\{\Phi s_{0}+C(T ; \Phi, \psi)+D(T ; \Phi, \psi) V_{0}+\lambda T\left[(1+\bar{k}) e^{k \theta 0(\Delta+-\varphi)}-1\right]\right\}
$$

where

$$
\begin{aligned}
C(T ; \Phi, \psi)- & {[\mu-\lambda \bar{k}] \Phi T-\frac{\alpha T}{\sigma_{\nu}^{2}}\left(\rho \sigma_{\nu} \Phi-\beta-\gamma\right) } \\
& -\frac{2 \alpha}{\sigma_{v}^{2}} \ln \left[1+1 / 2(\rho \sigma, \Phi-\beta-\gamma) \frac{1-e^{\gamma T}}{\gamma}\right]-\frac{2 \alpha}{\sigma_{v}^{2}} \ln [1-K(\Phi) \Psi]
\end{aligned}
$$




$$
\begin{aligned}
& D(T ; \Phi, \psi)-\frac{-2\left(c_{v}-1 / 2\right) \Phi-\Phi^{2}}{\rho \sigma_{v} \Phi-\beta+\gamma \frac{1+e^{\gamma T}}{1-e^{\gamma T}}}+\frac{\Lambda(\Phi) \psi}{1-x(\Phi) \psi}, \\
& y=\sqrt{\left(\rho \sigma_{v} \Phi-\beta\right)^{2}-2 \sigma_{v}^{2}\left[1 / 2 \Phi^{2}+\left(c_{v}-1 / 2\right) \Phi\right]}, \\
& \Lambda(\Phi)-\frac{\left(\frac{e^{Y T}+1}{e^{Y T}-1}\right)^{2}-1}{\left(\frac{e^{y T}+1}{e^{y^{T}}-1}+\frac{\beta-p \sigma_{\nu} \Phi}{y}\right)^{2}} \\
& K(\Phi)=\frac{\sigma_{v}^{2}}{\gamma \frac{e^{\gamma T}+1}{e^{\gamma T}-1}+\beta-\rho \sigma_{v} \Phi}
\end{aligned}
$$

The moment generating functions underlying the marginal transition densities of $s_{T}$ and $V_{T}$ are of course given by $F(\Phi, 0 ; T)$ and $F(0, \downarrow ; T)$, respectively. ${ }^{27}$

In principle, the joint transition densities can be evaluated via Fourier inversion of the joint moment generating function:

$$
p\left(s_{T}, V_{T} \mid s_{0}, V_{0}\right)-\frac{1}{(2 \pi)^{2}} \int_{--}^{-} \int_{--}^{-} F(i \Phi, i \psi ; T) e^{-i \Phi s_{T}-i \psi V_{T}} d \psi d \Phi
$$

However, it is more efficient to integrate out with respect to $\downarrow$ :

$$
\frac{1}{2 \pi} \int_{--}^{-}(1-k i \psi)^{\frac{-2 \varepsilon}{\sigma^{2}}} \exp \left[\frac{\Lambda V_{0} i \psi}{1-k i \psi}-i \psi V_{T}\right] d \psi-\frac{2}{k} p_{x^{2}}\left(\frac{2 V_{T}}{k} ; \frac{4 \alpha}{\sigma_{v}^{2}}, \frac{2 \Lambda V_{0}}{\kappa}\right)
$$

${ }^{27}$ For $\Phi=0, \Lambda=e^{-2 T}$ and $x=1 / 2 \sigma_{*}^{2}\left(1-e^{-\beta x}\right) / \beta$. 
where

$$
P_{x}(y ; v, \zeta)-1 / 2 e^{-y / 4}\left(y+0\left(\frac{y}{\zeta}\right)^{\frac{1}{2}\left(\frac{x}{3}-1\right)} I_{\frac{y}{3}-1}(\sqrt{y \zeta})\right.
$$

and $I_{t a-1}(\cdot)$ is the complex-valued modified Bessel function of the first kind of real order $1 / 2 \nu-1$. Expression $(B 14)$ is the complex-valued generalization (given complex-valued $\alpha(i \Phi)$ and $\Lambda(i \Phi)$ and real-valued $v=$ $\left.f \alpha / \sigma_{v}^{2}\right)$ of the non-central chi-squared density, and has the series representation

$$
p_{z}(y ; v, \zeta)-\frac{e^{-k(y+0)} y^{1 / 2 v-j}}{2^{1 / z v}} \sum_{j=0}^{-} \frac{(1 / 4 y \zeta)^{j}}{\Gamma(1 / 2 v+j) j !}
$$

where $\Gamma(\cdot)$ is the gamma function."

The joint transition density $\left.p\left(s_{T}, V_{T}\right\} s_{0}, V_{0}\right)$ can therefore be evaluated by univariate numerical integration:

$$
\begin{aligned}
& p\left(s_{r}, V_{r} \mid s_{0}, V_{0}\right)- \\
& \quad \frac{1}{2 \pi} \int_{-}^{-} F(i \Phi, 0 ; T) \frac{2}{K(i \Phi)} p_{\chi^{2}}\left(\frac{2 V_{T}}{K(i \Phi)} ; \frac{4 \alpha}{\sigma_{v}^{2}}, \frac{2 \Lambda(i \Phi) V_{0}}{K(i \Phi)}\right) e^{-i \Theta_{T}} d \Phi
\end{aligned}
$$

The result is real-valued, given a symmetric real component and anti-symmetric imaginary component. The joint transition density $p\left(s_{r} . \ln V_{T} \mid s_{0}, V_{0}\right)$ used in the estimations is related to (B17) by

"IMSL's routine DCBIS can evaluate the complex-valued Bessel function in (B13), but unfortunately is not accurate for all parameter values. The applications above consequently evaluate (B15) using two-sided summation, starting at the $n$th term where $n$ is approximately the positive root of

$$
n^{2}+n(1 / 2 v-1)-|1 / 4 y \lambda|=0,
$$

and $\|z\|$ is the modulus of $z$. 


$$
p\left(s_{T}, \ln V_{T} \mid s_{0}, V_{0}\right)=V_{\tau} p\left(s_{T}, V_{T} \mid s_{0}, V_{0}\right)
$$

which has finite density everywhere even when the reflecting barrier at $\boldsymbol{V}=0$ is attainable $\left(2 \alpha<\sigma_{v}^{2}\right)$. 


\section{References}

Akgiray, V. and G. G. Booth (1988). "Mixed Diffusion-Jump Process Modeling of Exchange Rate Movements," Review of Economics and Storistics 70:4, Nov. 631-637.

Bailey, Warren and René M. Stulz (1989). The Pricing of Stock Index Options in a General Equilibrium Model," Journal of Financial and Quantitative Analysis 24:1, March, 1-12.

Baillie, Richard T., and Tim Bollerslev (1989). The Message in Daily Exchange Rates: A Conditional Variance Tale," Journal of Business and Economic Statistics 7, 297.305.

Bates, David S. (1988a). "The Crash Premium: Option Pricing Under Asymmetric Processes, With Applications to Options on Deutschemark Futures," Rodiney L. White Center working paper 36-88, October.

(1988b). "Pricing Options Under Jump-Diffusion Processes," Rodney L. White Center working paper $37-88$, October.

(1991). "The Crash of '87: Was It Expected? The Evidence from Options Markets," Journal of Finance 46:3, July, 1009-1044.

Ben Khelifa, Zhouhaeir (1991). "Essays in International Finance," Chapter 1, Wharton School dissertation.

Bodurtha, James N., Jr., and Georges R. Courtadon (1987). "Tests of an American Option Pricing Model on the Foreign Currency Options Market, "Journal of Financial and Quantitarive Analysis 22:2, June, 153-167.

Bollerslev, Tin, Ray Y. Chou, and Kenneth F. Kroner (1992). "ARCH Modeling in Finance: A Review of the Theory and Empirical Evidence," Journal of Econometrics 52, 5-59.

Bossaerts, Peter and Pierre Hillion (1993). "A Test of a General Equilibrium Stock Option Pricing Model," Mothematical Firance, forthcoming.

Campa, Jose M. and P.H.Kevin Chang (1993). Testing the Expectations Hypothesis on the Term Structure of Implied Volatilities in Foreign Exchange Options," New York University working paper, March.

Cao, Charles (1992). "Pricing Foreign Currency Options with Stochastic Volatility," University of Chicago working paper, November.

Chesney, Marc and Louis Scott (1989). "Pricing European Currency Options: A Comparison of the Modified Black-Scholes Model and a Random Variance Model," Journal of Financial and Quantitative Analysis 24:3, Sept., 267-284.

Cox, John C., Jonathan E. Ingersoll, and Stephen A. Ross (1985). "A Theory of the Term Structure of Interest Rates," Econometrica 53:2, March, 385-407.

Cox, John C. and Mark Rubinstein (1985). Options Markets. Englewood Cliffs, NJ: Prentice-Hall.

Dumas, Bernard (1989). "Two-Person Dynamic Equilibrium in the Capital Market," Review of Financial Studies 2:2, 157-188. 
Feller, William (1971). An Introduction to Probability Theory and Its Applications, volume II, 2nd edition. New York: John Wiley and Sons.

Froot, Kenneth A. and Richard H. Thaler (1990). "Anomalies: Foreign Exchange," Journal of Economic Perspectives 4, 179-192.

Garman \& Kohlhagan (1983). "Foreign Currency Option Values," Journal of International Money and Finance 2, 231-237.

Heston, Steve (1993). "A Closed-Form Solution for Options With Stochastic Volatility," Review of Financial Studies 6, 327-344.

Hodrick, Robert J. The Empirical Evidence on the Efficiency of Forward and Futures Foreign Exchange Markets. New York: Harwood Academic Publishers.

Hsieh, David A. (1984). Tests of Rational Expectations and No Risk Premium in Forward Exchange Markets," Journal of International Economics 17, 173-184.

(1988). "The Statistical Properties of Daily Foreign Exchange Rates: 1974-1983," Journal of International Economics 2-, 129-145.

Hull, John and Alan White (1987). "The Pricing of Options on Assets with Stochastic Volatility," Journal of Finance 42:2, June, 281-300.

(1988). "An Analysis of the Bias in Option Pricing Caused by Stochastic Volatility," Advances in Furures and Options Reseurch 3, 29-61.

Ingersoll, Jonathan E. (1987). Theory of Financial Decision Making. Savage, MD: Rowman \& Littlefield. Jorion, Philippe (1988). "On Jump Processes in the Foreign Exchange and Stock Markets," Review of Financial Studies 1:4, 427-445.

Knoch, Hans-Jurgen (1990). "The Pricing of Foreign Currency Options with Stochastic Volatility," Yale School of Organization and Management working paper, April.

Meese, Richard A. (1986). "Testing for Bubbles in Exchange Markets: A Case of Sparkling Rates?" Journal of Political Economy 94:2, April, 345-373.

Melino, Angelo and Stuart Turnbull (1990). "Pricing Foreign Currency Options with Stochastic Volatility," Journal of Econometrics $45,239-265$.

Merton, Robert C. (1976). "Option Pricing when Underlying Stock Returns are Discontinuous," Journal of Financial Economics 3:1/2, Jan/March, 125-144.

Nelson, Daniel B., 1990, "ARCH Models as Diffusion Approximations," Journal of Econometrics 45, July/Aug., 7-38.

Rogalski, R.J. and J.D. Vinso (1978). "Empirical Properties of Foreign Exchange Rates," Journal of International Business Studies 9:2, 69-79. 
Scott, Louis O. (1987) "Option Pricing When the Variance Changes Randomly: Theory, Estimation, and an Application," Journal of Financial and Quantitative Analysis 22, 419-438.

(1993) Pricing Stock Options in a Jump-Diffusion Model with Stochastic Volatility and Interest

Rates: Applications of Fourier Inversion Methods," University of Georgia working paper, May.

Shastri. Kuldeep and Kulpatra Wethyavivorn (1987). The Valuation of Currency Options for Alternate Stochastic Processes," Journal of Financial Research 10:4, Winter, 283-293.

Stein, Elias M and Jeremy C. Stein (1991). "Stock Price Distributions with Stochastic Volatility: An Analytic Approach," Review of Financial Siudies 4, 727-752.

Stein, Jeremy C. (1989). "Overreactions in the Options Market," Journal of Finance 44, 1011-1023.

Westerfield, J.M. (1977). "Empirical Properties of Foreign Exchange Rates Under Fixed and Floating Rate Regimes," Journal of International Economics 7, 181-200. 
Table I

Performance of various models and submodels

\begin{tabular}{|c|c|c|c|c|}
\hline \multirow[t]{2}{*}{ Model } & \multirow[t]{2}{*}{ Parameters } & \multicolumn{2}{|c|}{$\begin{array}{l}\text { Root mean squared error (as } \\
\text { a percentage of the underlying } \\
\text { spot exchange rate) }\end{array}$} & \multirow{2}{*}{$\begin{array}{l}\mathrm{H}_{0} \text { : } \\
\text { Subsample } \\
\text { stability } \\
\text { (F-stat) }\end{array}$} \\
\hline & & $\begin{array}{l}\text { Parameters } \\
\text { estimated on } \\
\text { full sample } \\
(1984-91)\end{array}$ & $\begin{array}{l}\text { Paramelers } \\
\text { estimated on } \\
\text { 2-year sub- } \\
\text { samples }\end{array}$ & \\
\hline "Black-Scholes" & $\left\{V_{t}\right\}$ & $.0955 \%$ & $.0955 \%$ & \\
\hline $\begin{array}{l}\text { Delerministic vola- } \\
\text { tility }\end{array}$ & $\left\{V_{r}\right\}, \alpha, \beta^{*}$ & $.0916 \%$ & $.0867 \%$ & $F_{6, \infty}=357^{* *}$ \\
\hline Stochastic volatility & $\left\{V_{1}\right\}, \alpha, \beta^{*}, \sigma_{n} \rho$ & $.0896 \%$ & $.0838 \%$ & $F_{12, \infty}=225^{* *}$ \\
\hline $\begin{array}{l}\text { Stochastic volatility/ } \\
\text { jump-diffusion }\end{array}$ & $\begin{array}{c}\left\{V_{1}\right\}, \alpha, \beta^{*}, \sigma_{\infty} \rho, \\
\lambda *, \bar{k}^{*}, \delta\end{array}$ & $.0893 \%$ & $.0832 \%$ & $F_{21,0}=136^{* *}$ \\
\hline \multicolumn{2}{|c|}{$\mathrm{H}_{0}:$ no jumps (F-stat) } & $F_{3, \ldots}=40.1^{* *}$ & $F_{12, \infty}=21.4^{* *}$ & \\
\hline
\end{tabular}

* "Statistically significant at all standard significance levels.

Parameters were estimated using nonlinear least squares on a panel dala set of 19,689 call and put transactions for different strike prices and maturities on 372 Wednesday mornings over January 4, 1984 . June 19, 1991. Implicit instantaneous variances $\{V\}$ were estimated daily for all models. Other parameters $\theta$ were estimated in two fashions:

1) Constant over the full $1984-91$ sample

2) Different estimates $\theta_{413, \ldots}, \theta_{90-91}$ for biannual subsamples.

With an exchange rale of 50 \&/DM, a reduction in RMSE of $.01 \%$ represents an improvement in siandard errors of $0.005 \& / D M$, or $1 / 2$ price tick. 


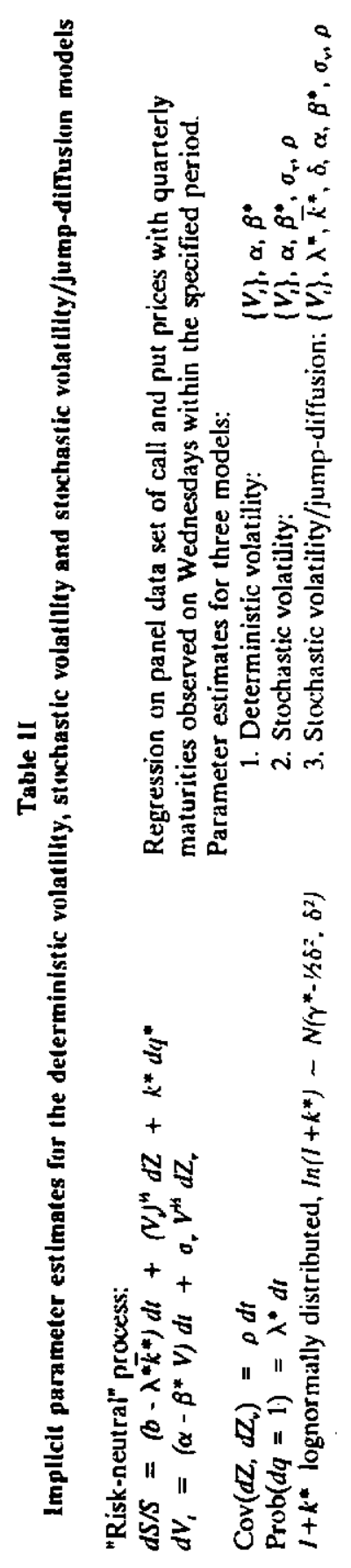

\begin{tabular}{|c|c|c|c|c|}
\hline 荝 & 登 & $\begin{array}{l}\text { 账 } \\
\text { 器 }\end{array}$ & 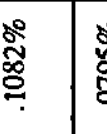 & 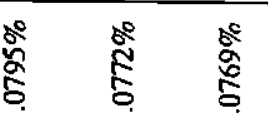 \\
\hline 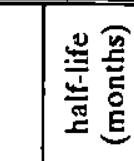 & ๘ & $\bar{\infty} \widehat{\widehat{c}}$ & $\infty$ : & ن \\
\hline$\frac{3}{\frac{3}{2}}$ & 口. & 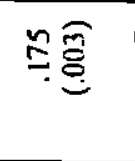 & $\tilde{8}:$ & 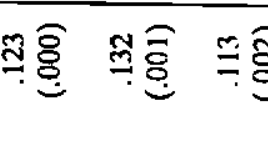 \\
\hline 。 & e & 五言 & 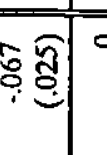 & 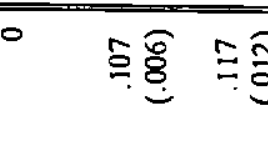 \\
\hline$\therefore$ & 0 & 琼 & : & 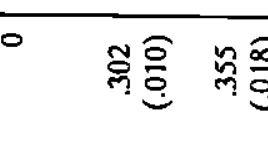 \\
\hline$\therefore$ & $\bar{\Phi}$ & 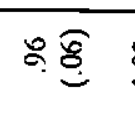 & है: & 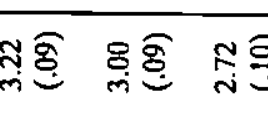 \\
\hline 。 & 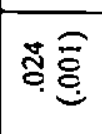 & ชิ & क्वे: & 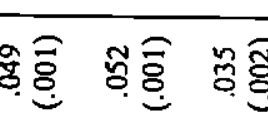 \\
\hline $\begin{array}{l}i \\
3 \\
\end{array}$ & & & & 0 \\
\hline${ }^{\circ}$ & $\overline{\sigma o}$ & $\overline{0 \quad}$ & क्⿹ & 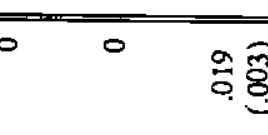 \\
\hline- & & $\circ \quad$ & की & $\circ$ वे \\
\hline 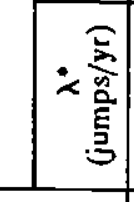 & & & केष्ठ & - సฮี \\
\hline & $\vec{a}$ & is & 3 & 3 正 \\
\hline & 垔 & & $\stackrel{\varpi}{\Xi}$ & \\
\hline
\end{tabular}




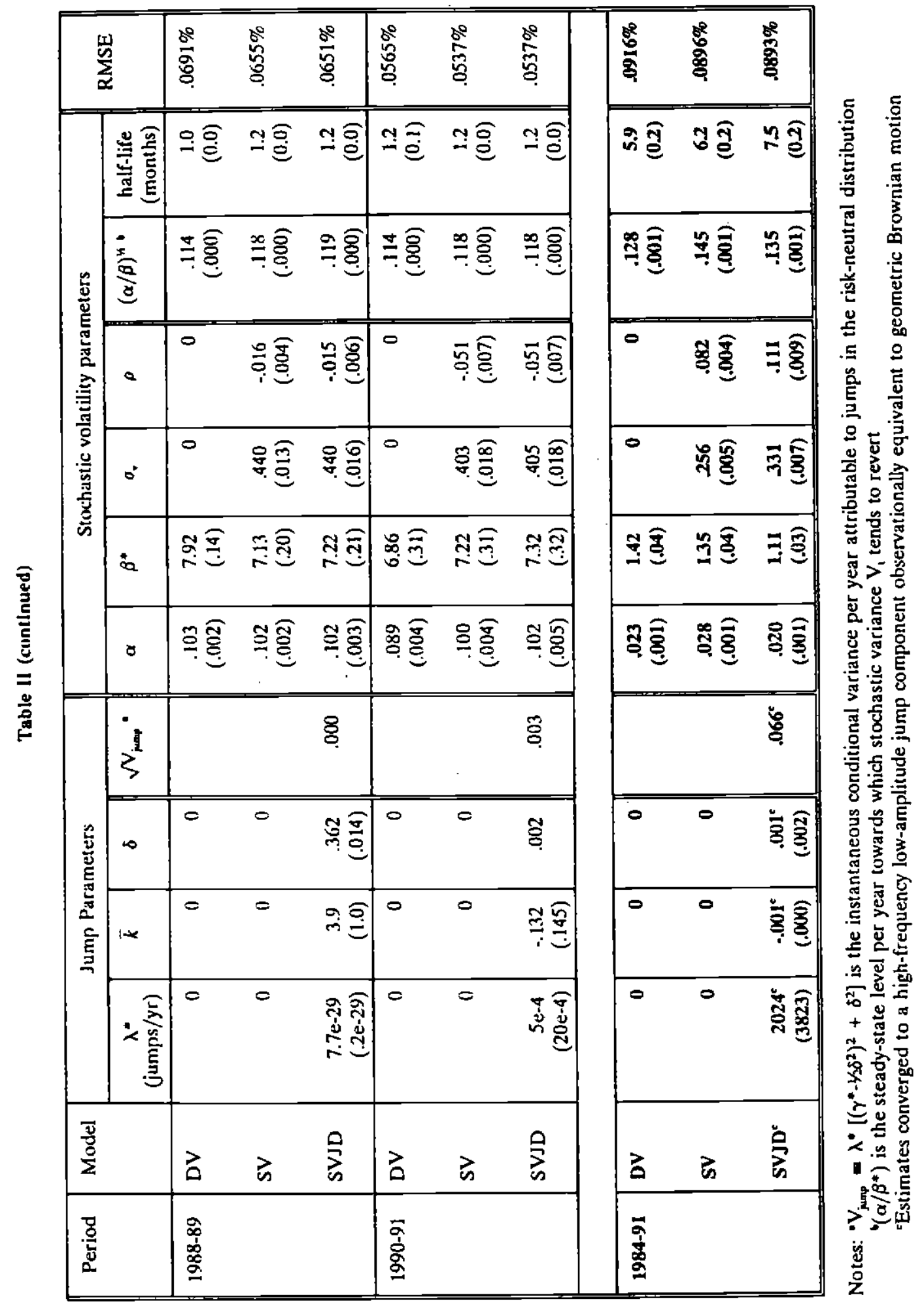


Table III

Average pricing errors of the stochastic volatility/jump diffusion model,

as a function of the option's moneyness $(F / X)$ and the time to expiration, in weeks.

Pricing error defined as actual - fitted value, in U.S. cents per DM. Minimum price tick is $.01 \mathrm{a} / \mathrm{DM}$. Data set consisted of 11,952 call transactions and 7,737 put transactions.

\begin{tabular}{|c|c|c|c|c|c|c|}
\hline \multirow{2}{*}{$\begin{array}{c}\text { call options } \\
\text { Maturity }\end{array}$} & \multicolumn{6}{|c|}{ Moneyness (F/X ratio) } \\
\hline & $<.94$ & $.94-.98$ & $.98-1.02$ & $1.02-1.06$ & $>1.06$ & all strike prices \\
\hline $\begin{array}{c}54 \text { weeks } \\
5-8 \text { weeks } \\
9-12 \text { weeks } \\
13-16 \text { weeks } \\
17-20 \text { weeks } \\
21-24 \text { weeks } \\
>24 \text { weeks }\end{array}$ & $\begin{array}{r}0.008 \\
0.016 \\
0.011 \\
-0.006 \\
-0.003 \\
-0.015 \\
-0.008 \\
\end{array}$ & $\begin{array}{r}0.017 \\
0.006 \\
0.001 \\
-0.007 \\
0.002 \\
-0.009 \\
-0.002 \\
\end{array}$ & $\begin{array}{r}0.007 \\
-0.002 \\
0.001 \\
-0.003 \\
0.006 \\
0.007 \\
0.015 \\
\end{array}$ & $\begin{array}{l}-0.016 \\
-0.007 \\
-0.008 \\
-0.011 \\
-0.031 \\
-0.011 \\
-0.001 \\
\end{array}$ & $\begin{array}{l}-0.017 \\
-0.035 \\
-0.031 \\
-0.025 \\
-0.038 \\
-0.042 \\
-0.043 \\
\end{array}$ & $\begin{array}{r}0.004 \\
-0.001 \\
-0.001 \\
-0.007 \\
-0.004 \\
-0.004 \\
0.004 \\
\end{array}$ \\
\hline all maturities & 0.002 & 0.003 & 0.002 & -0.013 & -0.029 & -0.001 \\
\hline \multicolumn{7}{|l|}{ put options } \\
\hline $\begin{array}{c}\text { S4 weeks } \\
5-8 \text { weeks } \\
9-12 \text { weeks } \\
13-16 \text { weeks } \\
17-20 \text { weeks } \\
21-24 \text { weeks } \\
>24 \text { weeks }\end{array}$ & $\begin{array}{l}-0.033 \\
0.010 \\
-0.027 \\
-0.062 \\
-0.063 \\
-0.074 \\
-0.112 \\
\end{array}$ & $\begin{array}{l}-0.013 \\
-0.016 \\
-0.005 \\
-0.034 \\
-0.061 \\
-0.032 \\
-0.143 \\
\end{array}$ & $\begin{array}{r}0.018 \\
-0.003 \\
-0.002 \\
-0.001 \\
-0.008 \\
-0.008 \\
-0.008 \\
\end{array}$ & $\begin{array}{l}0.019 \\
0.013 \\
0.012 \\
0.007 \\
0.007 \\
0.001 \\
0.002 \\
\end{array}$ & $\begin{array}{r}0.013 \\
0.022 \\
0.020 \\
0.016 \\
0.012 \\
0.002 \\
-0.020 \\
\end{array}$ & $\begin{array}{r}0.016 \\
0.006 \\
0.007 \\
0.002 \\
0.003 \\
-0.003 \\
-0.014 \\
\end{array}$ \\
\hline all maturities & -0.038 & -0.020 & 0.004 & 0.012 & 0.014 & 0.1007 \\
\hline
\end{tabular}




\begin{tabular}{|c|c|c|c|c|c|}
\hline & 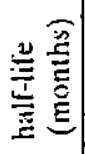 & 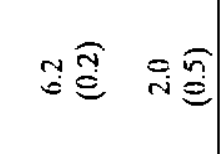 & 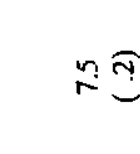 & 需 \\
\hline & & $\frac{5}{3}$ & 埕 & $\overparen{8}$ & $\underset{\Xi}{\Xi}$ \\
\hline \multirow{5}{*}{ 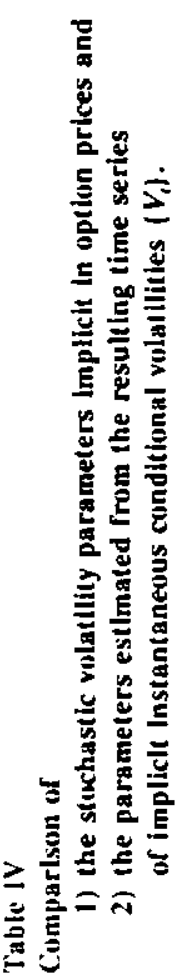 } & \multirow{4}{*}{ 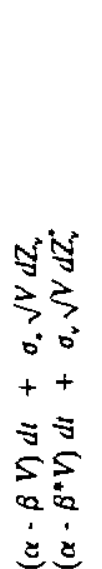 } & $0^{2}$ & 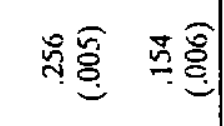 & 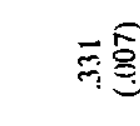 & 客 \\
\hline & & $\infty$ & $\begin{array}{l}\tilde{\sigma} \\
\stackrel{\sigma}{\Xi}\end{array}$ & & $\approx \sqrt{6}$ \\
\hline & & 英 & 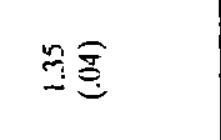 & \multicolumn{2}{|c|}{$\equiv \widehat{\Xi}$} \\
\hline & & $a$ & 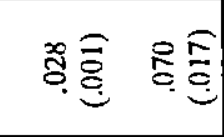 & 局 & 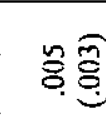 \\
\hline & 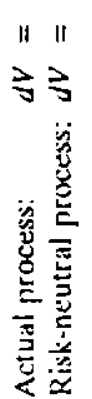 & $\overline{\underline{\underline{z}}}$ & 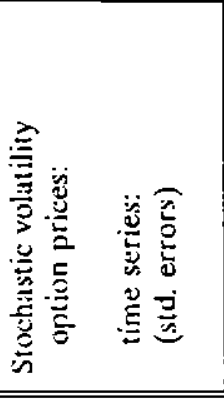 & 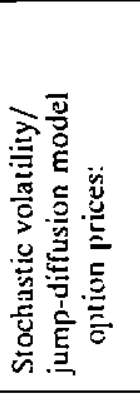 & 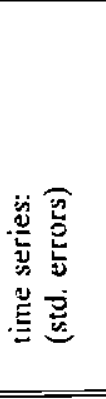 \\
\hline
\end{tabular}




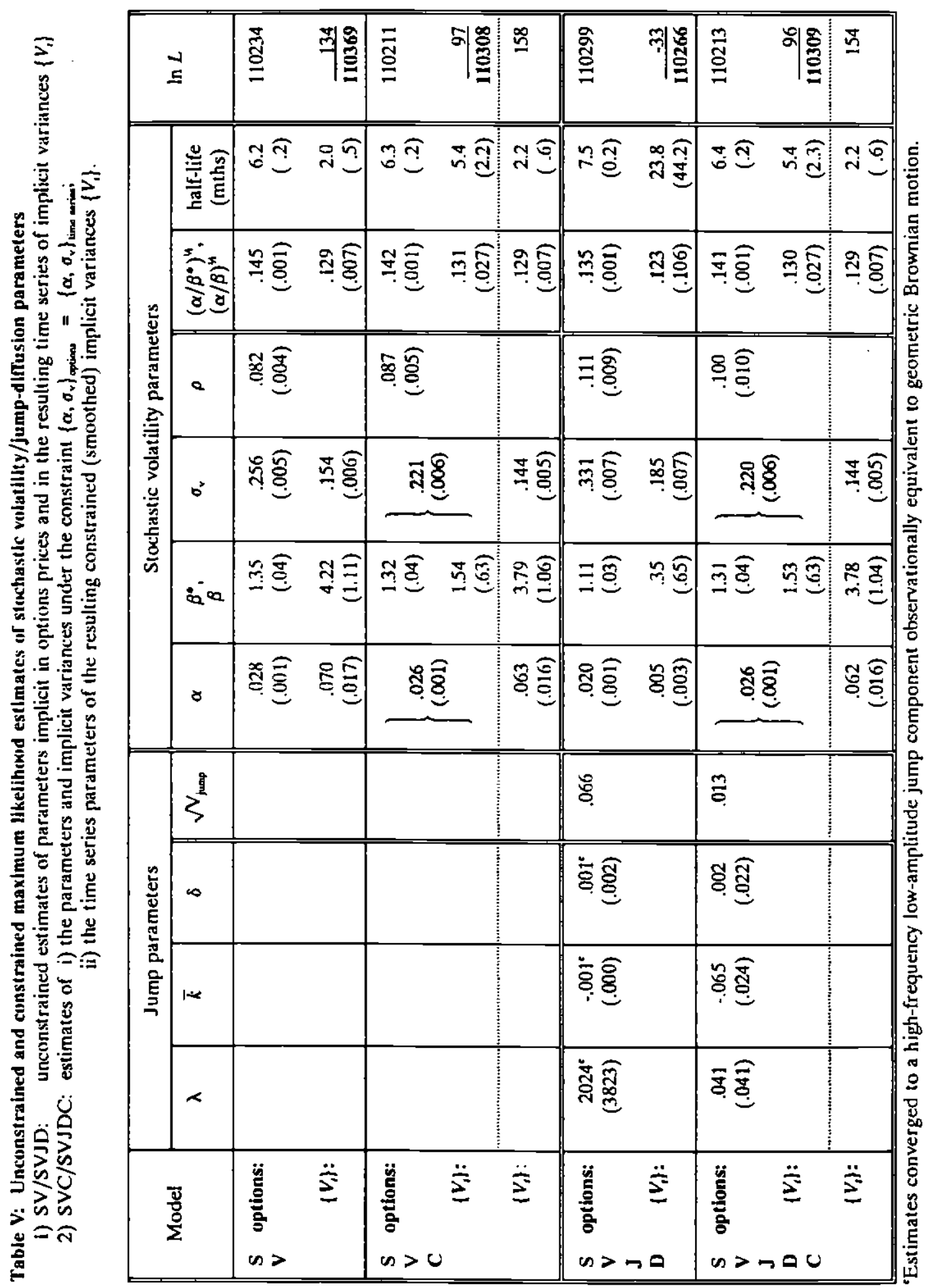




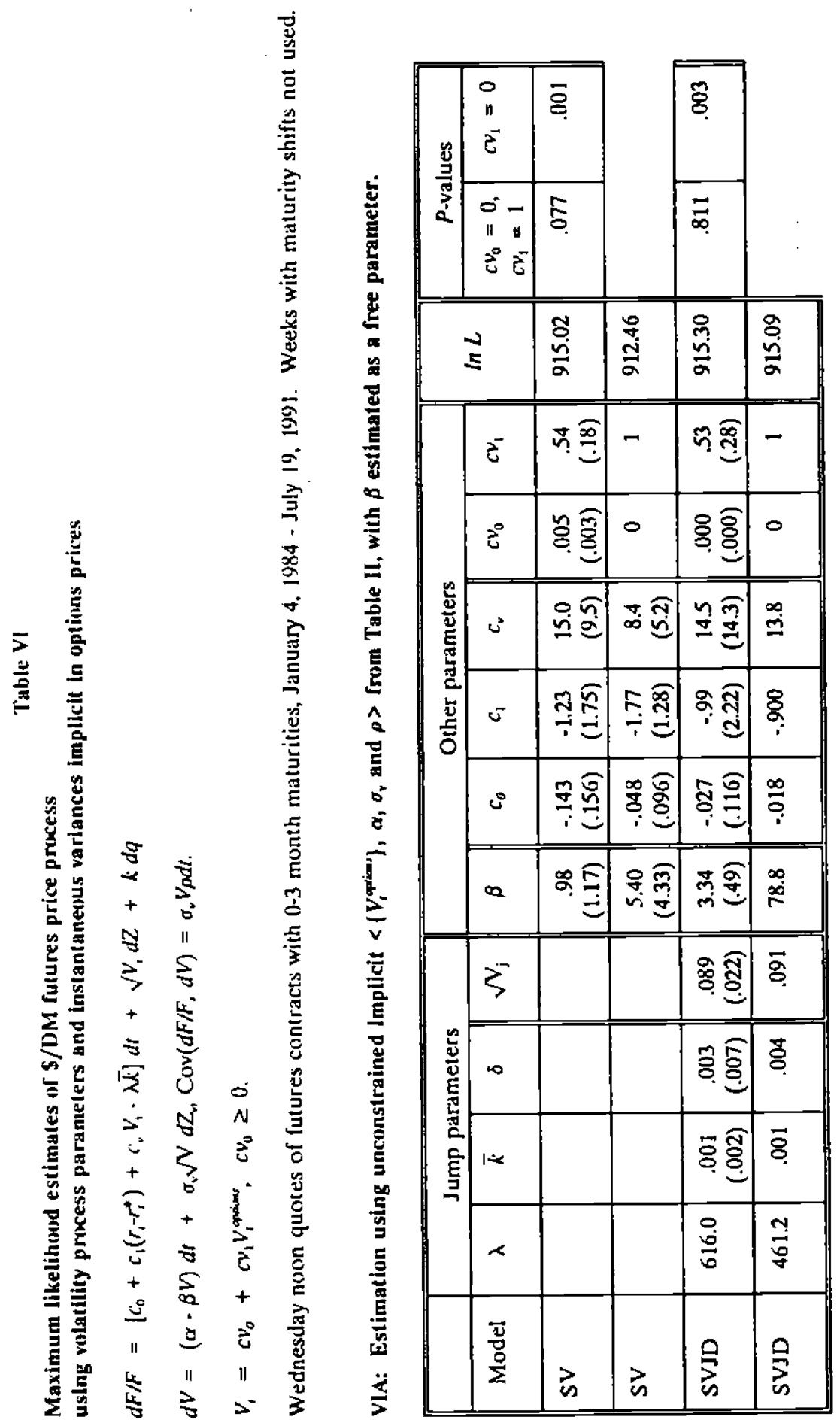




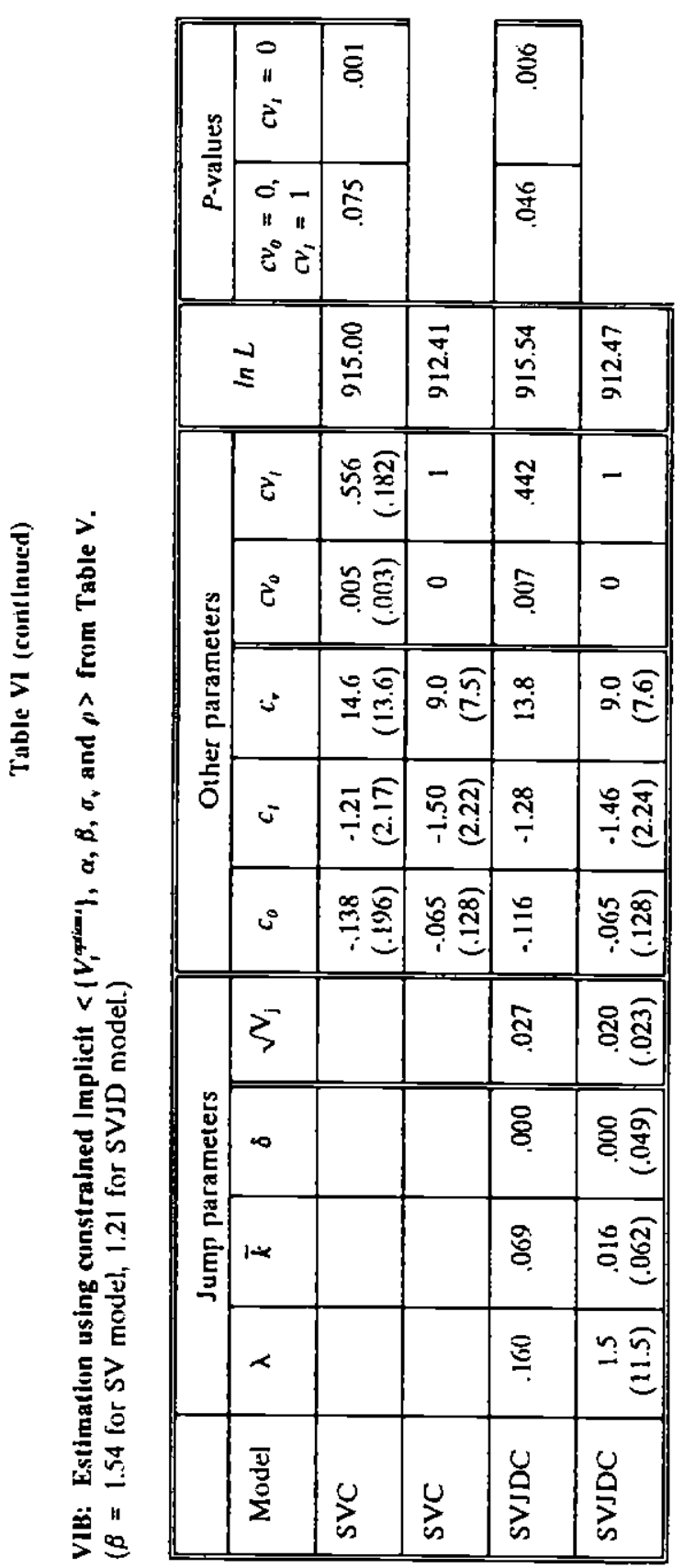




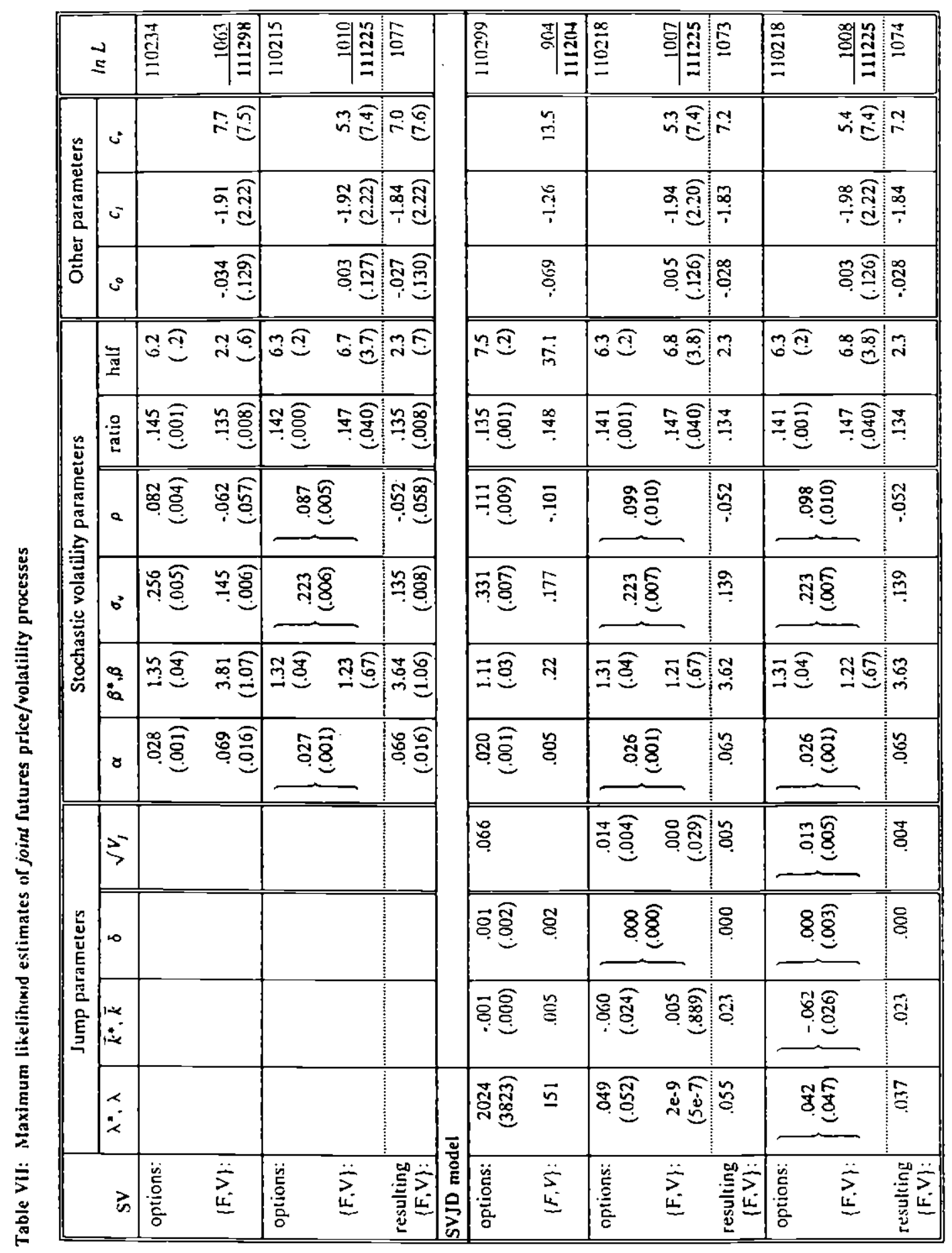


Table VII

Summary statistics for log-differenced weekly exchange rates

Period:

January 1974 - January 1984 .

Series:

December 1985

June 1991

S/DM exchange $\quad$ S/DM futures price

rate

(Jorion 1989)

Number of observations

626

359

Mean (percent per annum)

$.7 \%$

$3.8 \%$

Standard deviation (percent, annualized)

$10.3 \%$

$12.0 \%$

Skewness

.251

$.388^{*}$

Kurtosis

$6.29 *$

$3.96^{*}$

H0: no jumps

- Significant at the 1 percent level.

rejecled (a) 1\% level 
Figure 1

\section{Implicit instantaneous volatilities}

Stochastic volatility and stochastic volatility/jump-diffusion models

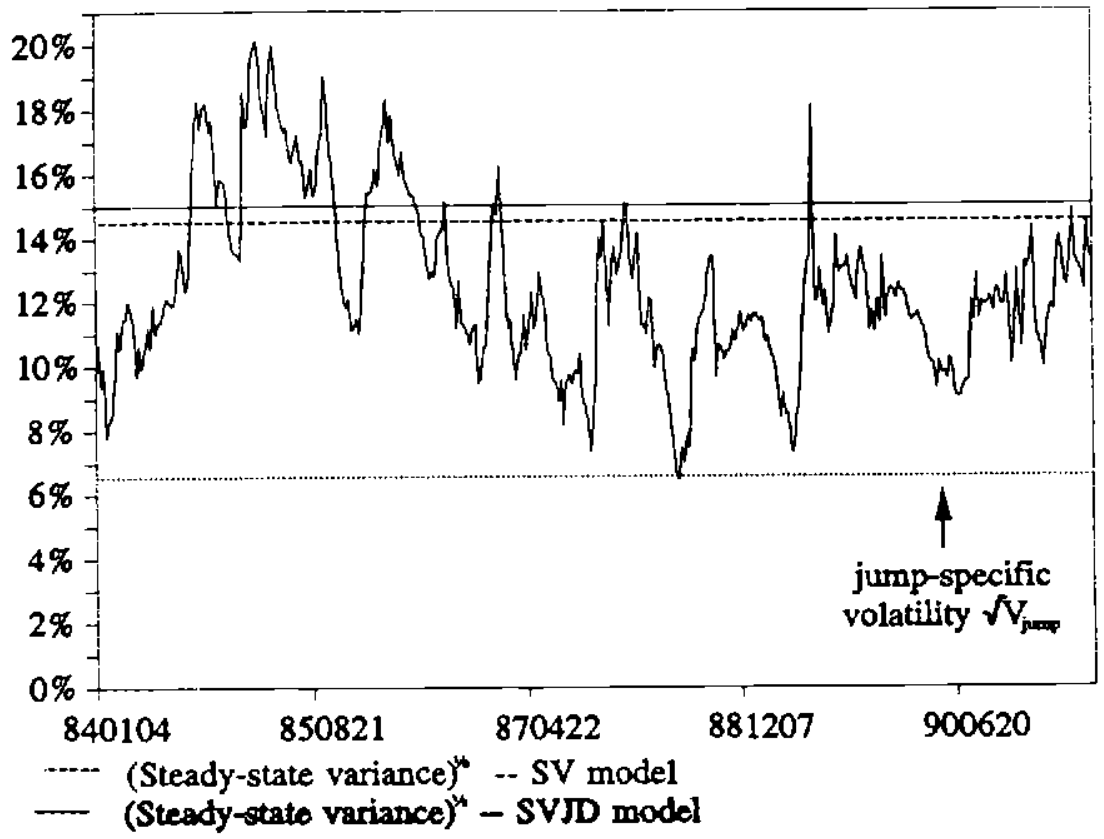

Graph shows

1) the instantaneous implicit volatilities $\sqrt{ } V$, from the stochastic volatility (SV) model

2) the instantaneous implicit volatilities $\left[V_{\text {mp }}+V_{\mathrm{t}}\right]^{4}$ from the stochastic volatility/jump-diffusion (SVJD) model

The two implicit instantaneous volatilities are indistinguishable.

The steady-state level:

$$
\begin{aligned}
& \left(\alpha / \beta^{*}\right)^{n} \quad \text { for the SV model, } \\
& {\left[\mathrm{V}_{\text {jump }}+\left(\alpha / \beta^{*}\right)\right]^{\prime n} \text { for the SVJD model. }}
\end{aligned}
$$

The expected average volatility, which corresponds closely to the Black-Scholes implicit volatility, is intermediate between the instantaneous and steady-state levels. 
Figure 2

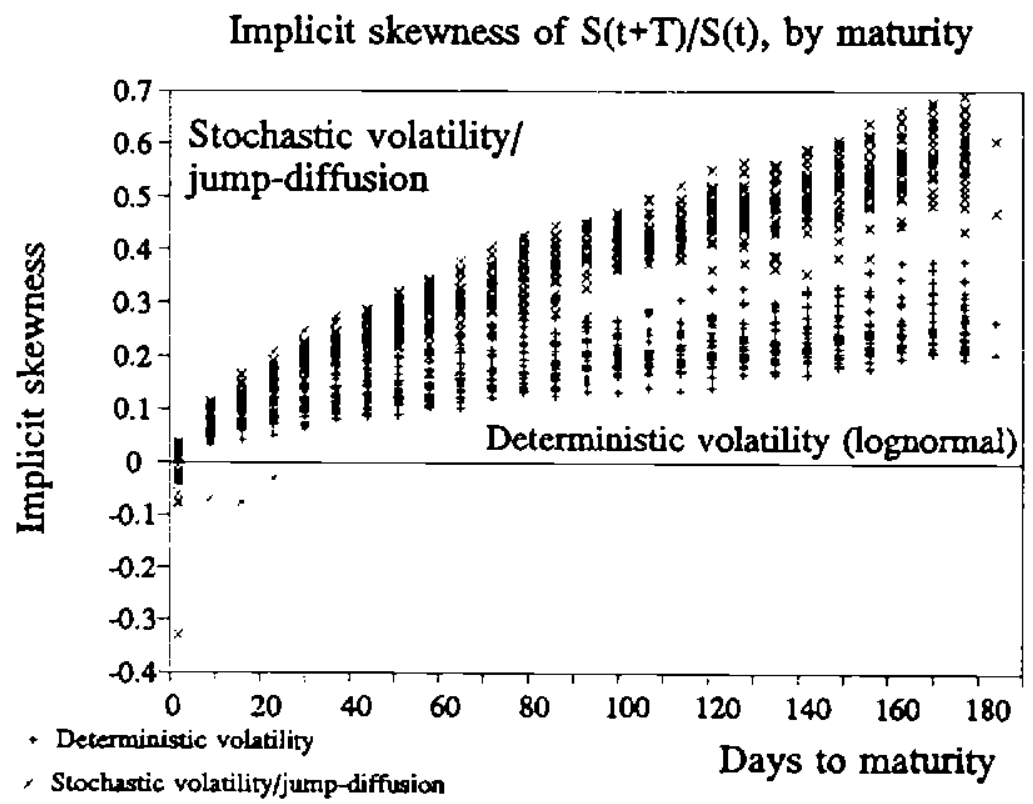

Figure 3

Implicit kurtosis of $S(t+T) / S(t)$, by maturity

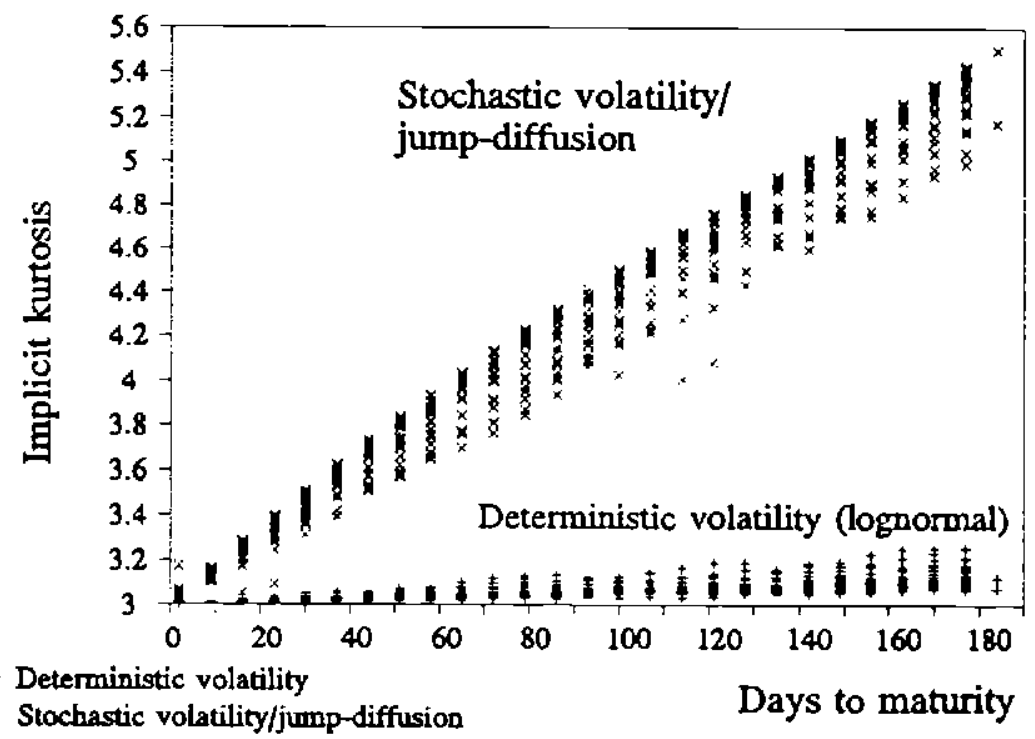


Figure 4

Unconditional distribution of instantaneous variances

SV model: sample and theoretical histograms

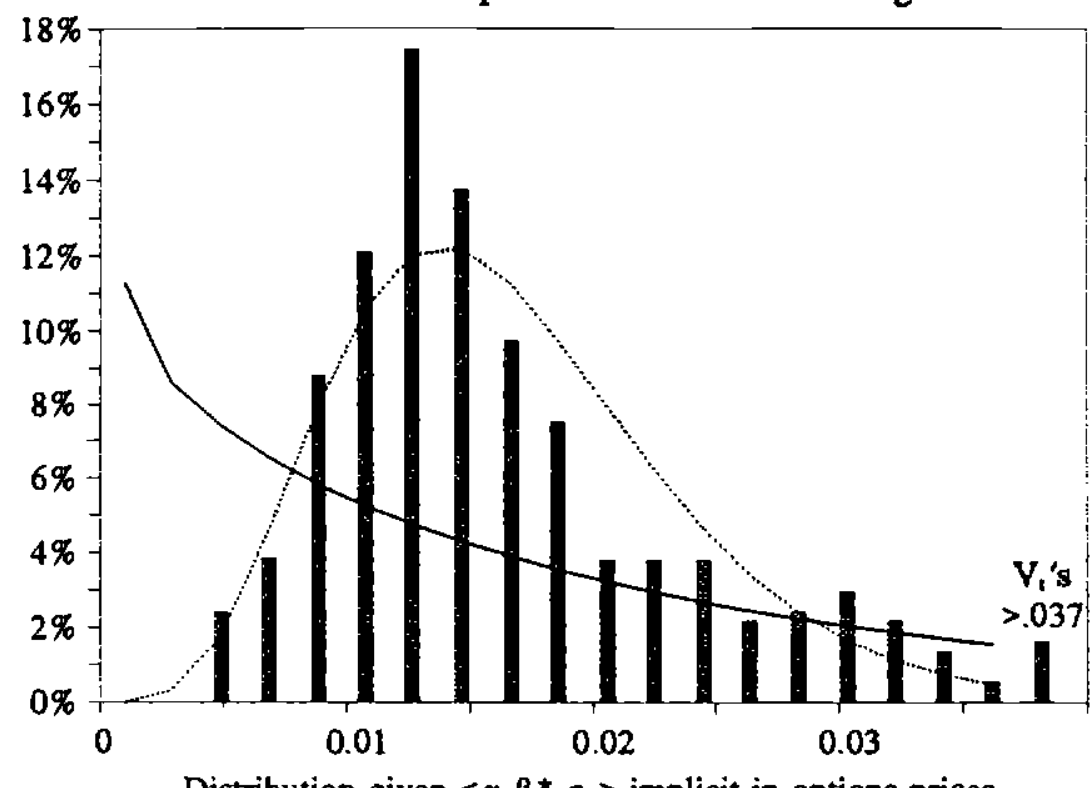

Distribution given $\left\langle\alpha, \beta^{\star}, \alpha_{v}\right\rangle$ implicit in options prices

Distribution given $\left\langle\alpha, \beta, \alpha_{2}\right\rangle$ estimated from $\left|V_{1}\right|$ time series 